\title{
Surface Albedo of the Antarctic Sea Ice Zone
}

\author{
Richard E. Brandt AND STEPHen G. WARREN \\ Department of Atmospheric Sciences, University of Washington, Seattle, Washington
}

ANTHONY P. WORBY

Australian Antarctic Division, and Antarctic Climate and Ecosystem Cooperative Research Centre, Hobart, Tasmania, Australia

Thomas C. GRENFELL

Department of Atmospheric Sciences, University of Washington, Seattle, Washington

(Manuscript received 30 September 2004, in final form 28 February 2005)

\begin{abstract}
In three ship-based field experiments, spectral albedos were measured at ultraviolet, visible, and nearinfrared wavelengths for open water, grease ice, nilas, young "grey" ice, young grey-white ice, and first-year ice, both with and without snow cover. From the spectral measurements, broadband albedos are computed for clear and cloudy sky, for the total solar spectrum as well as for visible and near-infrared bands used in climate models, and for Advanced Very High Resolution Radiometer (AVHRR) solar channels. The all-wave albedos vary from 0.07 for open water to 0.87 for thick snow-covered ice under cloud. The frequency distribution of ice types and snow coverage in all seasons is available from the project on Antarctic Sea Ice Processes and Climate (ASPeCt). The ASPeCt dataset contains routine hourly visual observations of sea ice from research and supply ships of several nations using a standard protocol. Ten thousand of these observations, separated by a minimum of 6 nautical miles along voyage tracks, are used together with the measured albedos for each ice type to assign an albedo to each visual observation, resulting in "ice-only" albedos as a function of latitude for each of five longitudinal sectors around Antarctica, for each of the four seasons. These ice albedos are combined with $13 \mathrm{yr}$ of ice concentration estimates from satellite passive microwave measurements to obtain the geographical and seasonal variation of average surface albedo. Most of the Antarctic sea ice is snow covered, even in summer, so the main determinant of area-averaged albedo is the fraction of open water within the pack.
\end{abstract}

\section{Introduction}

Antarctic sea ice appears to be an important player in climate change (e.g., Rind et al. 1995; Holland and Bitz 2003; Holland et al. 2001), and knowledge of its albedo is needed for accurate simulations of climate (Meehl and Washington 1990; Rind et al. 1997). The input of solar energy to the ocean is limited by reflection of sunlight by the snow/ice system. In most parts of the Antarctic sea ice zone, the oceanic surface flow is divergent, exposing open water in the form of leads and polynyas. In summer the open water persists, but in the

Corresponding author address: Richard Brandt, Department of Atmospheric Sciences, University of Washington, Box 351640, Seattle, WA 98195-1640.

E-mail: brandt@atmos.washington.edu cold seasons new ice can form rapidly. In most regions at most times there is usually a great variety of ice types of varying thickness and snow cover, with a corresponding variety of albedo values.

When the sea surface temperature drops to $-1.9^{\circ} \mathrm{C}$, small plate-like crystals called frazil begin to form. A thick slurry of frazil crystals damps the smallest waves and thus alters the visual appearance of the surface to resemble an oil slick; this is called grease ice. In calm water the slurry solidifies into a sheet of randomly oriented crystals a few centimeters thick, called nilas, with a high concentration of bubbles and brine inclusions; these are effective at scattering light. Nilas grows downward into the water column as congelation ice, whose crystals become substantially oriented with c-axes horizontal; congelation ice is clearer than the surface frazil layer. 
In the presence of significant wind and waves, a continuous sheet cannot form; the crystals instead aggregate into rounded discs called pancakes, up to $1 \mathrm{~m}$ or more in diameter and several tens of centimeters thick. With further cooling and damping of the waves, the pancakes eventually freeze to their neighbors, thereafter thickening further by the congelation process. The thickness of the uppermost layer of randomly oriented crystals is therefore much greater in pancakes than in nilas.

Extensive coherent sheets called floes, resulting either from aggregation of pancakes or thickening of nilas, continue to thicken by freezing to the base in winter. Ice that has grown through an entire winter is first-year ice. A special category of first-year ice is fast ice, which is fastened to a coastline and therefore immobile. Definitions and photographs of the various forms of sea ice are given by the World Meteorological Organization (1970), Armstrong et al. (1973), Steffen (1986), and Worby (1999).

Synoptic storms are common in the Southern Ocean, so new ice does not remain snow-free for long. At first, the snow can be patchy because of wind drifting. When the average snow depth becomes thick enough to provide a continuous cover (about $3 \mathrm{~cm}$ ), the albedo is thereafter determined by the snow depth and grain size; very little sunlight reaches the ice below. Even without snowfall from storms, "frost flowers" can form on thin nilas exposed to cold air (Perovich and Richter-Menge 1994). Their effect on albedo is similar to that of a thin snow layer.

There are important hemispheric and regional differences in the frequencies of the different ice types. Andreas and Ackley (1982) pointed out that melt ponds (or puddles), which are common in summer in the Arctic Ocean, are almost nonexistent in the Antarctic. In the Arctic summer, the snow cover melts first; thereafter bare ice is exposed, which melts from above. In the Antarctic, by contrast, a larger heat flux from the ocean, together with colder and drier air, causes the ice to melt predominantly from the bottom up. This means that the melting ice retains its snow cover until it becomes so thin that it can no longer provide a stable platform for the snow, or until the ice areal concentration becomes sufficiently low that wave action can splash water onto small floes, forming slush.

The albedo measurements reported here were made on three voyages of the Australian National Antarctic Research Expeditions (ANARE), in OctoberDecember 1988 on the Icebird, in SeptemberNovember 1996 on the Aurora Australis, and in December 2000 on the Polar Bird. The measurements of 1988 were reported by Allison et al. (1993, hereafter
ABW). The 1996 measurements sampled some types of ice that had not been encountered in the 1988 voyage. The 2000 voyage sampled melting snow, providing our only albedos for summer conditions. Brief reports of the 1996 voyage were given by Warren et al. (1997) and Brandt et al. (1999), and some of their albedos were used by Warren et al. (2002). A table of recommended albedos was given by ABW; here we provide updated tables that are more comprehensive and more accurate. We then combine these albedo values with ship-based reports of the frequency of occurrence of the different ice types, and satellite analyses of ice fractional coverage, to develop a seasonal climatology of albedo and its geographical variation in the ocean surrounding Antarctica.

\section{Field program}

The voyages on which spectral albedo measurements were made began in Hobart, Tasmania, Australia. The ships traveled southwest to near Casey Station $\left(110^{\circ} \mathrm{E}\right)$ on the coast of East Antarctica, then west to Davis Station $\left(75^{\circ} \mathrm{E}\right)$ on Prydz Bay, and finally returning on a direct route to Hobart. The 1988 voyage approached Mawson Station $\left(66^{\circ} \mathrm{E}\right)$ as well, west of Prydz Bay. The 2000 voyage went only to Casey Station. In the sea ice zone, the longitudes covered by the three voyages were $60^{\circ}-112^{\circ} \mathrm{E}$.

\section{a. Visual observations}

Hourly visual observations of sea ice conditions were reported during all three voyages using a standard protocol. The fractional coverage is reported for as many as four ice types for the region within a 1-km radius of the ship. The ice thickness and snow thickness are estimated for ice floes broken and overturned by the ship, by comparison to a ball of known diameter hanging close to the water level. This protocol was introduced by Allison (1989). It is now being used widely throughout the Antarctic sea ice zone by research and supply ships of many nations and has been formally defined by the Scientific Committee for Antarctic Research (SCAR) in the program on Antarctic Sea Ice Processes and Climate (ASPeCt; Worby 1999; Worby and Allison 1999; Worby and Dirita 1999). Sea ice types reported in the hourly observations are listed in Table 1 along with their defined thickness ranges.

\section{b. Instrumentation}

On the 1988 and 1996 voyages, spectral albedo was measured using a radiometer covering the wavelength region 320-1060 nm. Solar flux from within a hemispherical field of view is redirected by the radiometer's 
TABLE 1. Representative all-wave solar albedos of surface types in the East Antarctic sea ice zone in spring and summer. Values in bold are derived from measurements; all others were interpolated or extrapolated using Fig. 5. The seasons are indicated by SON and DJF.

\begin{tabular}{|c|c|c|c|c|c|c|c|c|c|c|c|}
\hline \multirow[b]{3}{*}{ Ice type } & \multirow{3}{*}{$\begin{array}{l}\text { Ice thickness } \\
(\mathrm{cm})\end{array}$} & & & \multicolumn{4}{|c|}{ Thin snow $(<3 \mathrm{~cm})$} & \multicolumn{4}{|c|}{ Thick snow $(>3 \mathrm{~cm})$} \\
\hline & & \multicolumn{2}{|c|}{ No snow } & \multicolumn{2}{|c|}{ Clear } & \multicolumn{2}{|c|}{ Cloudy } & \multicolumn{2}{|c|}{ Clear } & \multicolumn{2}{|c|}{ Cloudy } \\
\hline & & Clear & Cloudy & SON & DJF & SON & DJF & SON & DJF & SON & DJF \\
\hline Open water & 0 & 0.07 & 0.07 & - & - & - & - & - & - & - & - \\
\hline Grease & $<1$ & 0.09 & 0.09 & - & - & - & - & - & - & - & - \\
\hline Nilas & $<10$ & 0.14 & 0.16 & 0.42 & 0.39 & 0.45 & 0.42 & - & - & - & - \\
\hline Young grey ice & $10-15$ & 0.25 & 0.27 & 0.55 & 0.51 & 0.59 & 0.56 & 0.72 & 0.67 & 0.76 & 0.72 \\
\hline Young grey-white ice & $15-30$ & 0.32 & 0.34 & 0.64 & 0.59 & 0.68 & 0.64 & 0.76 & 0.70 & 0.81 & 0.76 \\
\hline First-year ice $<0.7 \mathrm{~m}$ & $30-70$ & 0.41 & 0.45 & 0.74 & 0.69 & 0.79 & 0.74 & 0.81 & 0.75 & 0.87 & 0.82 \\
\hline First-year ice $>0.7 \mathrm{~m}$ & $>70$ & 0.49 & 0.54 & 0.81 & 0.75 & 0.87 & 0.82 & 0.81 & 0.75 & 0.87 & 0.82 \\
\hline
\end{tabular}

cosine collector through the entrance aperture where it passes through 1 of 11 interference filters, each with 10-nm bandwidth, that are mounted on a filter wheel. The light is then detected by a silicon photodiode with extended ultraviolet sensitivity, and the signal is amplified to one of four choices of gain to maximize the signal-to-noise ratio. Dark current is measured at a blocked filter position on the filter wheel at each amplification level and recorded at the end of each scan. The dark current is then subtracted from the signal in postprocessing.

On the 2000 voyage, two additional near-infrared (NIR) spectral radiometers (Ocean Optics S2000 and Spectron Engineering 590) were used. These instruments increased our spectral resolution and extended our wavelength coverage to the range 320 to $1800 \mathrm{~nm}$, but with a gap between 1000 and $1115 \mathrm{~nm}$.

During the 1996 and 2000 field seasons, an Eppley precision spectral pyranometer was also used to monitor total solar irradiance. Both the spectral radiometer and the pyranometer were controlled by a Polycorder 516-C datalogger that sequenced the filter wheel, chose the optimal amplification level, and then stored concurrent spectral and broadband measurements. Under overcast sky the pyranometer measurements were used to check whether the incident solar flux was steady during the course of the spectral measurement. In a few cases, a correction for varying downward flux was made by applying a scale factor based on the pyranometer measurements.

\section{c. Platforms}

For albedo measurements over thick ice, the radiometer was mounted on a rod suspended $1 \mathrm{~m}$ above the ice, supported at each end by a tripod resting on the ice. However, most of the ice types to be studied were too thin to support the field team. For these measurements, the radiometer was mounted on the end of a 3-m rod supported on the inboard end by an aluminum frame. The frame could be mounted either in a cargo basket hung from the ship's crane or in a helicopter with a sliding window. This apparatus was designed to position the radiometers as far as possible horizontally from the basket or the helicopter, so that the ice being sampled would be minimally shadowed. The frame allowed positioning, leveling, and inverting of the radiometers. Most measurements were made under overcast sky, which minimizes errors due to inaccurate leveling of the instrument. When the sky was clear, most measurements were made within $2 \mathrm{~h}$ of solar noon to experience the maximum solar altitude, likewise minimizing errors due to imperfect leveling. The basket was hung off the sunny side of the ship, $20 \mathrm{~m}$ from the ship's hull, to avoid shadowing of the ice by the ship, and measurements were made from a location $4-10 \mathrm{~m}$ above the ice. Measurements from the helicopter were made from a hovering position $15-25 \mathrm{~m}$ above the ice. For measurements from both basket and helicopter, corrections due to the platform's obstruction of the instrument's field of view were required. For observations when the solar disk was visible, the instrumented rod was oriented toward the azimuth of the sun so that there was no shadowing by the crane structure or the helicopter body and rotors. For measurements from the basket, the corrections in 1988 were 3\%-6\% under clear sky and $11 \%$ under overcast sky (ABW). The use of a longer rod in 1996 reduced these corrections to $1 \%$ and $3 \%$, respectively.

\section{Spectral albedo measurements}

\section{a. Snow-free ice}

Figure 1 shows the spectral albedo measurements for snow-free ice and open water. The broadband solar 


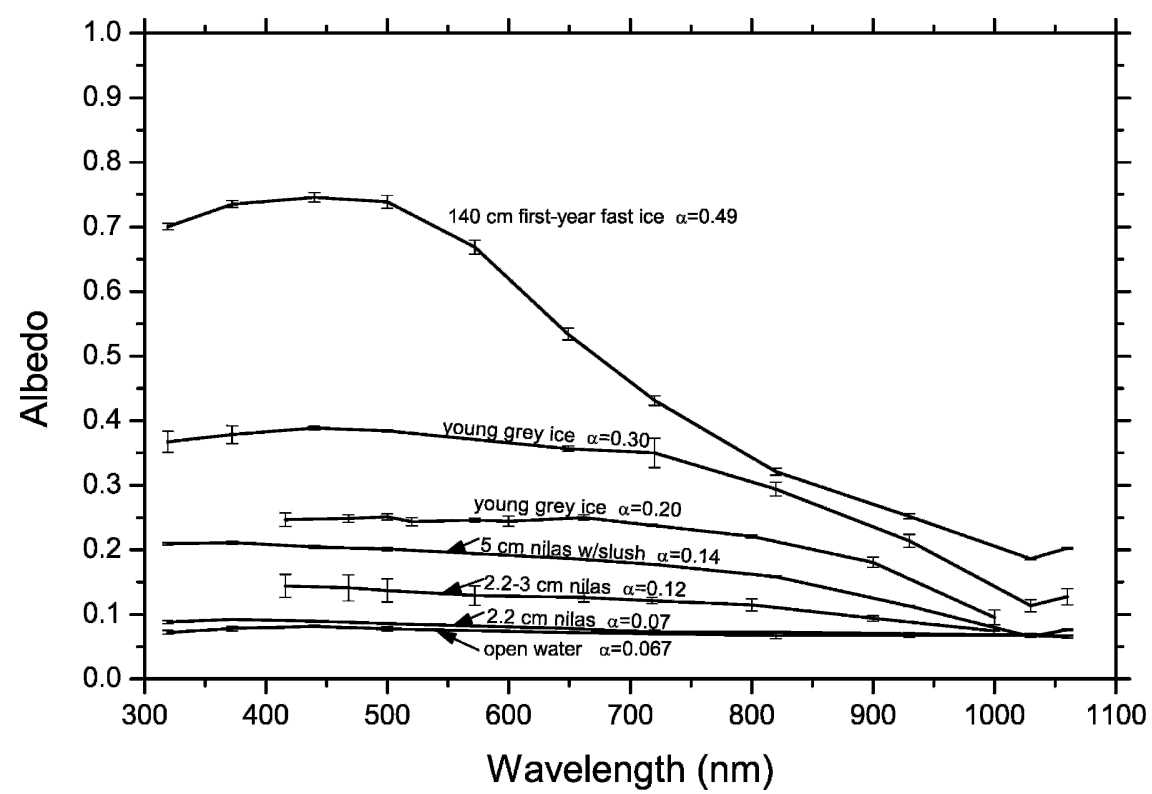

FIG. 1. Spectral albedos of snow-free ice and open water. Measurements from the 1996 voyage begin at $320 \mathrm{~nm}$; those from the 1988 voyage begin at $420 \mathrm{~nm}$. Broadband solar albedo $\alpha$ is also given. Ice thickness $Z_{i}$ is given, except for two ice types that were observed only from a helicopter. The curve for 2.2-3-cm nilas was included in Fig. 11 of ABW but was mislabeled there as "3-4 cm."

albedo, $\alpha$, is also given on each curve; its computation is explained below. On most of the curves, the ice thickness is also given. Measurement of ice thickness was possible by lowering the basket to the ice surface and collecting a sample; this was not possible from the helicopter.

The albedo of open water is due almost entirely to Fresnel reflection from the surface. The value is 0.07 , independent of wavelength, as expected for diffuse incident radiation on water with a refractive index of 1.33 , and in agreement with measurements by others (Katsaros et al. 1985; Kondratyev 1969; Payne 1972; Briegleb and Ramanathan 1982; Pegau and Paulson 2001).

The albedo of 2-cm-thick nilas is almost indistinguishable from that of water. As the ice thickens, the albedo increases at all wavelengths. The greatest increase is between 400 and $500 \mathrm{~nm}$. The scattering of light by bubbles and brine inclusions is nearly independent of wavelength because these scatterers are much larger than visible wavelengths, so the spectral variation of albedo is determined by the absorption spectrum of ice (Grenfell 1983). The absorption coefficient of ice reaches a minimum at $470 \mathrm{~nm}$ (Grenfell and Perovich 1981), so the albedo peaks at this wavelength. There is a local maximum of absorption at $1030 \mathrm{~nm}$, which accounts for the minimum of albedo at that wavelength. [The albedo rises to a minor peak at 1060 $\mathrm{nm}$ and then continues its general decrease (Grenfell and Perovich 1984; Grenfell et al. 1994b).]

\section{b. Effect of snow cover}

In the Antarctic, ice thicker than nilas is usually snow covered. However, at one location we did have the opportunity to measure thick first-year ice that was free of snow. This was fast ice, $140 \mathrm{~cm}$ thick, near the coast of the Vestfold Hills, north of Davis Station. It was at a location where strong wind funneled between icebergs, keeping the ice free of snow. The spectral albedo plot for this ice, the uppermost curve in Fig. 1, is also shown in Fig. 2; the broadband albedo was 0.49 . Nearby was an area of patchy snow cover, $0-10 \mathrm{~mm}$ thick, and farther away the ice was completely covered by a snow layer of 5-10 mm depth. Their albedos are also shown in Fig. 2. The effect of a thin snow cover is dramatic, particularly in the NIR. Just 5-10 mm of continuous snow cover raised the broadband albedo from 0.49 to 0.81 , nearly as high as values measured for deep snow on the Antarctic Plateau, $\alpha=0.83$ (Grenfell et al. 1994b).

These results are corroborated by earlier measurements of Weller (1968) on fast ice at Mawson Station. $\mathrm{He}$ measured broadband solar albedo daily from $\mathrm{Au}-$ gust to November 1965 (Weller's Fig. 3.9). Wind often cleared the snow from the ice. On one occasion a new 


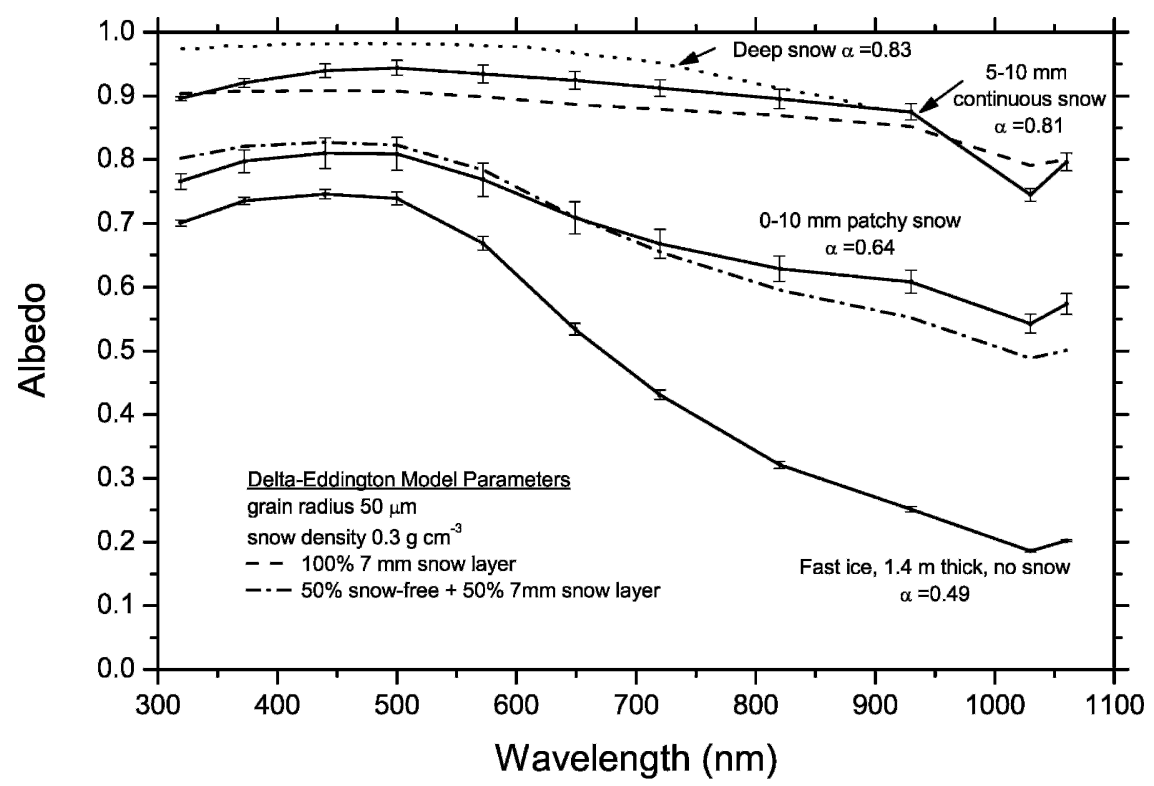

FIG. 2. Effect of a thin snow cover on the albedo of thick cold fast ice near Davis Station, 30 Oct 1996. The air temperature was $-5^{\circ} \mathrm{C}$. The lower curve is the same as the upper curve in Fig. 1, for bare ice that is $1.4 \mathrm{~m}$ thick. Nearby, the ice was covered with patchy snow or continuous snow; their albedos are also shown. The topmost curve, for deep snow on the Antarctic Plateau, is from Table 6 of Grenfell et al. (1994b). Spectral albedos computed using the delta-Eddington radiative transfer model (Wiscombe and Warren 1980) are also shown.

snowfall of $2-3 \mathrm{~cm}$ raised the albedo from 0.42 to 0.88 , and on another occasion a snowfall of $1-2 \mathrm{~cm}$ raised the albedo from 0.39 to 0.78 .

The measurements in Fig. 2 are adequately explained by a delta-Eddington radiative transfer model (Wiscombe and Warren 1980) for the observed snow grain radius of $50 \mu \mathrm{m}$, which is typical of cold wind-packed surface snow. The measured spectral albedo of the snow-free ice was specified as the lower boundary condition. The best fit to the observed albedo for the patchy snow area was a combination of $50 \%$ snow-free ice and $50 \%$ ice with a $7-\mathrm{mm}$ snow cover. For the area of continuous snow, the best fit was obtained with a continuous layer of 7-mm snow cover.

These results might suggest that any snow thickness greater than $1 \mathrm{~cm}$ should be classified as "thick snow" for the purpose of albedo. In the tables below, we instead use $3 \mathrm{~cm}$ as the minimum thickness for the thick snow category. This is because, for snow cover, the most important distinction is not its thickness but rather its areal coverage. Cold, fine-grained snow with an average thickness less than $3 \mathrm{~cm}$ is likely to be patchy because of wind drifting. In summer the snow does not drift, but the grain sizes are larger and sunlight penetrates deeper into the snowpack, so a uniform layer of less than $3 \mathrm{~cm}$ qualifies as "thin" (Fig. 13c of Wiscombe and Warren 1980).

\section{c. Melting snow}

Spectral albedo of melting snow, measured on two days in December 2000, is shown in Fig. 3. On each day, numerous repeated scans were made; their average is plotted. The ice was $1.4 \mathrm{~m}$ thick, covered by $30 \mathrm{~cm}$ of old melting snow with grain radii of about $1 \mathrm{~mm}$. This melting coarse-grained snow has lower albedo in the

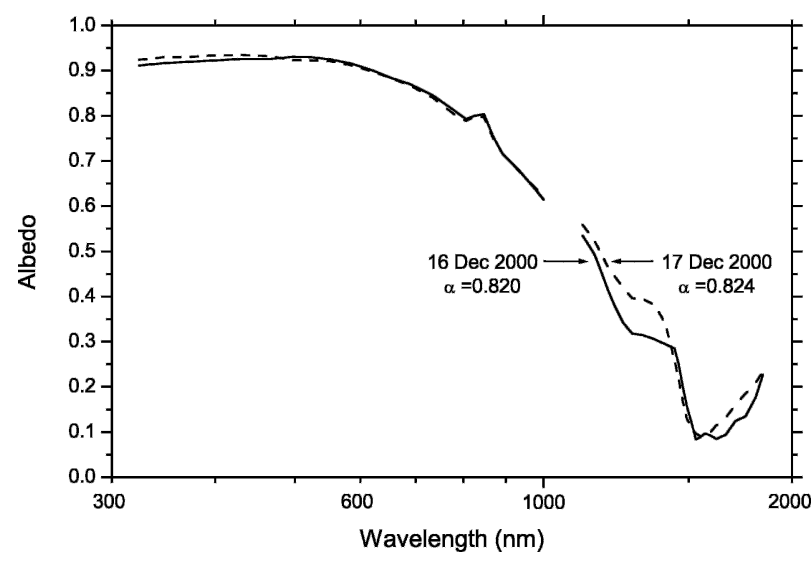

FIG. 3. Spectral albedo of melting snow in summer. The ice was $1.4 \mathrm{~m}$ thick, covered by $30 \mathrm{~cm}$ of old melting snow. Measurements were made under overcast cloud on 16 and 17 Dec 2000 at $64^{\circ} \mathrm{S}$, $105^{\circ} \mathrm{E}, 83 \mathrm{~km}$ from the coast of Antarctica. The broadband solar albedo is also given. 
near infrared than the cold fine-grained snow in Fig. 2, as expected. However, the visible albedo for the melting snow is lower than expected for pure deep snow of this grain size (Fig. 8a of Wiscombe and Warren 1980). There are two possible explanations for this: 1) the lower layers of the snow were waterlogged, making the effective thickness smaller (cf. Fig. 13c of Wiscombe and Warren 1980), or 2) absorptive impurities may have been present. These impurities could be continental dust from the ice-free regions of coastal Antarctica, $83 \mathrm{~km}$ away, or (more likely) algae that entered the snow via seawater flooding of the snow/ice interface (Fig. 11 of Grenfell et al. 1998). There may also have been biological material from seals, penguins, and other birds.

\section{Broadband and narrowband albedos}

\section{a. Computation of broadband albedo}

The measured spectral albedos are integrated over wavelength to obtain albedos for various bands used in remote sensing and in climate models, as well as the average broadband albedo for the entire solar spectrum, $\alpha$, also called "all-wave" albedo:

$$
\alpha=\frac{\int \alpha_{\lambda} F_{\lambda} d \lambda}{\int F_{\lambda} d \lambda}
$$

where $\alpha_{\lambda}$ is the measured spectral albedo and $F_{\lambda}$ is the downward solar spectral irradiance at wavelength $\lambda$.

We also often measured the broadband albedo directly using pyranometers. However, we prefer to obtain broadband albedo instead by integrating the spectral albedo measurements for two reasons. First, the spectral radiometer is more accurate because of the design of its cosine collector, its calibration, and its insensitivity to inversion. Second, using the spectral albedo we can compute the broadband albedo for any incident radiation spectrum, not just the sky condition at the time of the measurement. However, the integrated spectral albedo usually did agree closely with the pyranometer measurement.

To compute the broadband albedos, we use the method described by ABW. Spectra of $F_{\lambda}$ were computed for clear sky and for a stratus cloud of optical depth $\tau=11$, using an atmospheric radiative transfer model (ATRAD; Wiscombe et al. 1984). These spectra of $F_{\lambda}$ resemble those shown in Fig. 1 of Brandt and Warren (1993). For the broadband solar albedo, the limits of integration in (1) are 290-3000 nm, which ex- ceed the spectral range of the measurements, so we break the numerator into three parts:

$$
\alpha=\frac{\alpha_{\lambda 1} \int_{290}^{\lambda 1} F_{\lambda} d \lambda+\int_{\lambda 1}^{\lambda 2} \alpha_{\lambda} F_{\lambda} d \lambda+\alpha_{I R} \int_{\lambda 2}^{3000} F_{\lambda} d \lambda}{\int_{290}^{3000} F_{\lambda} d \lambda},
$$

where $\lambda 1$ and $\lambda 2$ are the range of wavelengths for the albedo measurements, $\alpha_{\lambda 1}$ is the estimated albedo at wavelengths below $\lambda 1$, and $\alpha_{\mathrm{IR}}$ is the estimated albedo at wavelengths above $\lambda 2$. For the 1988 field experiment, the measured wavelength range was $420-1000 \mathrm{~nm}$; in 1996 it was $320-1060 \mathrm{~nm}$, and in 2000 it was $320-1800$ $\mathrm{nm}$. For the near ultraviolet, we assume that the albedo between 290 and $320 \mathrm{~nm}$ is the same as the measured albedo at $320 \mathrm{~nm}$ (or for the 1988 measurements, the measurement at $420 \mathrm{~nm}$ is used for $290-420 \mathrm{~nm}$ ). This is reasonable, based on measurements and calculations of albedo over this spectral range, because absorption by ice is extremely weak (Perovich and Govoni 1991). For the near-infrared wavelengths not measured, we use the average of upper and lower bounds as described by $\mathrm{ABW}$. The uncertainty in $\alpha$ due to lack of measurement beyond $1000 \mathrm{~nm}$ was always $<0.02$, and in all but two cases it was $<0.01$. The uncertainty is small because the percentage of the solar spectrum at $\lambda>1000 \mathrm{~nm}$ is only $19 \%$ under clear sky and $10 \%$ under a typical cloud (optical thickness $\tau=11$ ).

\section{b. All-wave albedo of growing nilas}

The all-wave albedo of snow-free nilas is plotted versus ice thickness in Fig. 4, along with measurements of other investigators. In the optically thin limit, $\alpha$ increases linearly with optical depth (which is proportional to ice thickness if the ice is homogeneous). The solid line is a linear fit to the measurements for $Z_{i}<6$ $\mathrm{cm}$, forced to give $\alpha=0.07$ at $Z_{i}=0$ (the value for open water). For $Z_{i}>6 \mathrm{~cm}$, the relationship is no longer linear, and for bare ice $\alpha$ appears to increase in proportion to $\log Z_{i}$ (lower line in Fig. 5). This logarithmic relation is shown as the dashed line in Fig. 4. The scatter in Fig. 4 is mostly due to variability in nilas properties, such as size distribution of bubbles and depth of congelation ice formation. Frost flowers may also have been present in some of the Arctic measurements shown in Fig. 4, but they were absent in our measurements.

\section{c. Estimation of albedo for ice types not observed}

Not all combinations of ice type and snow thickness in the ASPeCt classification (Table 1) were available 


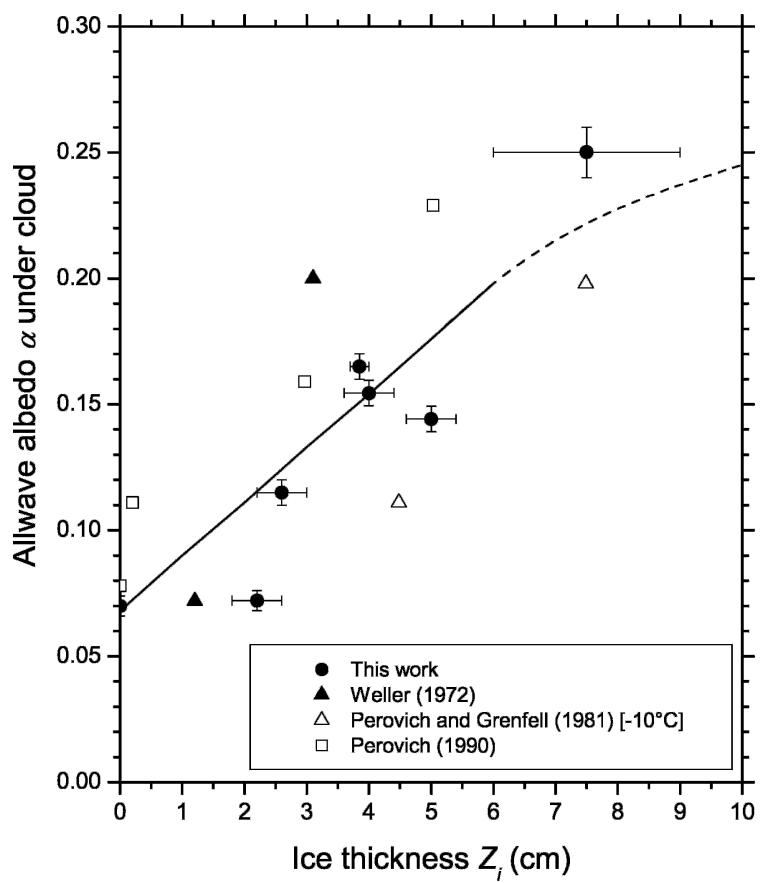

FIG. 4. Broadband solar albedo $\alpha$, as a function of ice thickness $Z_{i}$, for snow-free nilas. The solid line is a linear fit to the measurements for $Z_{i}<6 \mathrm{~cm}$, constrained to give $\alpha=0.07$ at $Z_{i}=0$ (the value for open water). For $Z_{i}>6 \mathrm{~cm}$, the dashed line shows the relationship obtained from Fig. 5, with $\alpha$ linear in $\log Z_{i}$. Our field measurements are compared to Arctic field measurements of Weller (1972) and Perovich (1990) and to laboratory measurements of Perovich and Grenfell (1981).

for measurement on the three voyages. The albedos for these types can be estimated by interpolation from plots of all-wave albedo versus the logarithm of ice thickness. Figure 5 displays the interpolations for allwave albedo under a cloudy sky. The increase of albedo with the logarithm of ice thickness is a smooth function that is nearly linear. By choosing the average thickness for each ice type, it is straightforward to interpolate values for the no-snow and thin-snow cases. However, all of our measurements of thick snow were over thick ice. To develop an interpolation and extrapolation procedure for the albedo of thick snow over thin ice, we are guided by a measurement from the Arctic. Perovich (1990) measured the spectral albedo of $20 \mathrm{~cm}$ young "grey" ice [as defined in WMO (1970)] with a 4-cm snow cover at wavelengths $400-1100 \mathrm{~nm}$ while monitoring the freezing of a newly opened lead. Putting these values into (2), we obtain the all-wave albedo under cloud, $\alpha=0.80$, shown in Fig. 5. It is somewhat lower than the value $\alpha=0.87$ we measured for thick snow over thick ice. Since thick snow is nearly opaque, can its albedo be affected at all by the thickness of the ice below? There is reason to think that it can, because

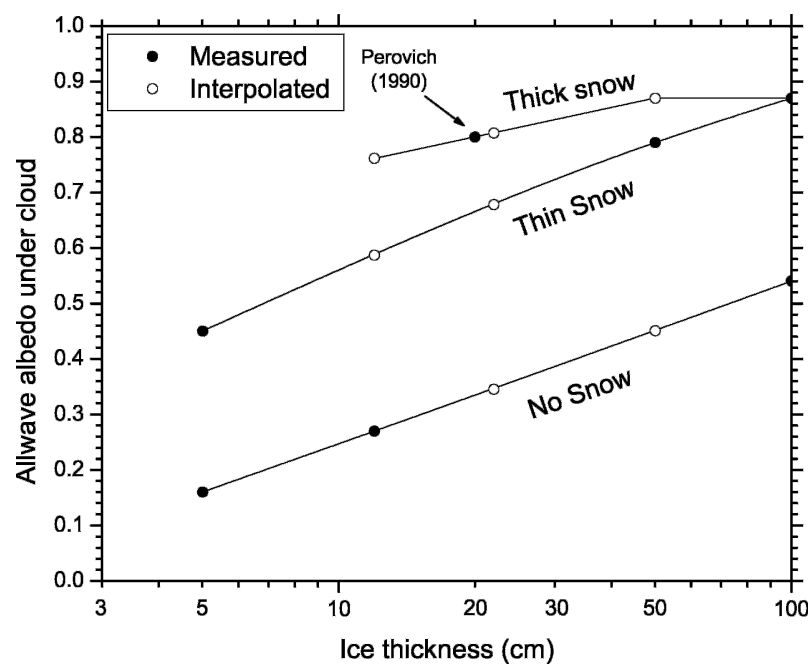

FIG. 5. Illustration of interpolation procedure to obtain estimates for albedo in Tables 1-3 in categories for which no albedo measurement was available. The measurements (filled circles) suggest a linear interpolation of albedo vs the logarithm of ice thickness. The albedo of ice covered by thick snow is assumed to asymptote at thin first-year ice $(30-70 \mathrm{~cm})$, as explained in the text. The points are plotted at the five values of ice thickness assumed for the middle of the ice thickness categories in Table 1 (nilas, grey, grey-white, thin first-year, and thick first-year).

the ice thickness can affect the character of the snow. If the ice is sufficiently thin, seawater can percolate upward and wick into the lower part of the snow layer, creating slush (Grenfell 1986; Grenfell et al. 1994a; Maksym and Jeffries 1996; Massom et al. 2001). In addition, thicker ice is likely to have thicker snow cover within the category of thick snow $\left(Z_{s}>3 \mathrm{~cm}\right)$. We assume that these processes are significant only for ice thinner than thin first-year ice (mean thickness of 50 $\mathrm{cm}$ ), so in Fig. 5 we keep the albedo constant from $Z_{i}=$ 100 to $50 \mathrm{~cm}$ and then use Perovich's point for interpolation and extrapolation to thinner ice.

\section{d. Recommended albedos for each category of ice}

Table 1 gives recommended all-wave albedos; that is, the average for the entire solar spectrum. Six ice types, plus open water, are identified in order of increasing thickness. For the ice types that can support a snow cover (nilas and thicker), three snow categories are defined: no snow, thin snow, and thick snow. As explained above in the discussion of Fig. 2, a continuous uniform snow cover of $1 \mathrm{~cm}$ is sufficient to hide the ice below. However, we choose a minimum average thickness of 3 $\mathrm{cm}$ for the snow to qualify as "thick," because wind drifting of thinner snow layers is likely to cause patchiness. [For a typical snow density, $3 \mathrm{~cm}$ of snow corresponds to about $1 \mathrm{~g} \mathrm{~cm}^{-2}$.] This criterion is appropriate for cold windblown snow. Coarse-grained melting snow 
has a smaller scattering coefficient, so sunlight penetrates deeper and a greater thickness is required to hide the underlying ice. However, this distinction may not matter much in practice because most melting snow in the Antarctic summer is thicker than $3 \mathrm{~cm}$.

In each snow/ice category, albedos are given for both clear and cloudy sky. Clouds absorb near-infrared radiation at wavelengths where snow and ice are also absorptive (because all three media consist of water, they all exhibit the vibrational absorption bands of the water molecule). Sunlight that has passed through a cloud is therefore depleted in the wavelengths for which snow and ice have low albedo, so the spectrally averaged albedo is higher under cloud than under clear sky (Grenfell et al. 1981; Warren 1982). The values in Table 1 come from (1) applied to the measured spectral albedos $\alpha_{\lambda}$, using $F_{\lambda}$ obtained from the ATRAD model for a solar zenith angle of $66^{\circ}$. The cloudy-sky spectrum was computed for a cloud optical thickness $\tau=11$; this is typical for clouds in the Antarctic sea ice zone (Fitzpatrick et al. 2004).

The bold numbers in the table are derived from the measured spectral albedos. The other numbers are for snow/ice categories we did not have the opportunity to sample. They result from interpolation or extrapolation as explained above in the discussion of Fig. 5.

\section{1) Spring [SePtember-October-November $(\mathrm{SON})]$}

Table 1 is a revision of ABW's Table 2 (which was for springtime only) and shows some significant differences for that season:

1) The table in $\mathrm{ABW}$ has a misprint in the list of ice types: the boundary between thin first-year ice and thick first-year ice should be $0.7 \mathrm{~m}$ not $0.3 \mathrm{~m}$; it is given correctly in Table 1 here.

2) The new measurement of bare thick first-year ice, $\alpha=0.49$, provides a crucial data point allowing interpolation where ABW had to make a guess. This one measurement has caused us to alter the table entries for the thickest three categories of snow-free ice (using interpolation).

3) We have numerous measurements of nilas; its albedo depends mainly on thickness but also on other properties, as shown in Fig. 4. In the table we have given just the mean value of our measurements.

4) An ice sample with measured albedo of 0.32 was misclassified in ABW's table as young grey ice with thin snow. Reference to the 1988 logbook indicates that this ice was actually nilas with slush. It has been averaged together with other measurements of nilas with thin snow, to give $\alpha=0.42$ for the table. This had the consequence of raising all the values in the thin-snow column when the interpolation was done.

5) First-year ice $(<0.7 \mathrm{~m})$ with thick snow was shown in ABW's table with an albedo of 0.77. According to the reexamined logbook, the snow was actually patchy for this measurement, so we have moved it to the thin-snow category. Our remaining measurements on thick snow are all for thick ice, so the other table entries in the thick-snow column were obtained by interpolation using the measurement by Perovich (1990), as explained in the discussion of Fig. 5.

It is curious that our albedo $(\alpha=0.81)$ for thick first-year ice $(>0.7 \mathrm{~m})$ is the same for thin snow as for thick snow. The thin-snow measurement is from Fig. 2, with 5-10 mm snow, near Davis Station in October 1996 under clear sky. The thick-snow measurement is from $30 \mathrm{~cm}$ of snow over fast ice near Mawson Station in November 1988, also under clear sky, shown in Fig. 11 of ABW. The likely explanation for their equality is that the snow grains were larger at Mawson. Our visual estimates of grain radius were $50 \mu \mathrm{m}$ at Davis (as used in the radiative transfer modeling in Fig. 2) and $100 \mu \mathrm{m}$ at Mawson. A grain radius of $150 \mu \mathrm{m}$ for pure snow would appear necessary to explain the low albedo at Mawson, but impurities may have contributed to lowering the albedo, as numerous penguins were observed walking near the measurement site. Variations in grain size, impurities, and zenith angle can all affect the albedo, but their effects are minor compared to the major differences among categories shown in Table 1.

One common type of ice, pancakes, is conspicuously absent from Table 1. A field of pancakes is a mixed scene: partly water and partly ice. In the reporting protocol for visual ice observations, the areal fraction of water within a pancake field is given, as well as the ice thickness and snow thickness. The albedo assigned to pancakes is therefore an average of the albedos of water and either grey or grey-white ice, depending on thickness, weighted by their areal fractions.

A preliminary version of Table 1, for SeptemberOctober-November (SON) only, was published by Massom et al. (2001) as their Table 11. It differs slightly from Table 1 here.

\section{2) Summer [December-January-February (DJF)]}

For snow-covered ice in summer, we use the measurements in Fig. 3 to obtain the all-wave albedo of thick melting snow over thick first-year ice as $\alpha=0.75$ under clear sky and 0.82 under cloudy sky. These albedos are lower than the values for cold snow in SON, by 
TABLE 2. Representative albedos of surface types in the East Antarctic sea ice zone, in spring and summer, for AVHRR channels 1 and 2, for clear sky. Values in bold are derived from measurements; all others were interpolated or extrapolated using the method illustrated in Fig. 5.

\begin{tabular}{|c|c|c|c|c|c|c|c|c|c|c|}
\hline \multirow[b]{3}{*}{ Ice type } & & & \multicolumn{4}{|c|}{ Thin snow $(<3 \mathrm{~cm})$} & \multicolumn{4}{|c|}{ Thick snow $(>3 \mathrm{~cm})$} \\
\hline & \multicolumn{2}{|c|}{ No snow } & \multicolumn{2}{|c|}{ Channel 1} & \multicolumn{2}{|c|}{ Channel 2} & \multicolumn{2}{|c|}{ Channel 1} & \multicolumn{2}{|c|}{ Channel 2} \\
\hline & Channel 1 & Channel 2 & SON & DJF & SON & DJF & SON & DJF & SON & DJF \\
\hline Open water & 0.07 & 0.07 & - & - & - & - & - & - & - & - \\
\hline Grease & 0.10 & 0.08 & - & - & - & - & - & - & - & - \\
\hline Nilas & 0.17 & 0.14 & 0.49 & 0.46 & 0.44 & 0.39 & - & - & - & - \\
\hline Young grey ice & 0.30 & 0.24 & 0.64 & 0.60 & 0.59 & 0.52 & 0.79 & 0.74 & 0.78 & 0.68 \\
\hline Young grey-white ice & 0.38 & 0.28 & 0.73 & 0.68 & 0.68 & 0.59 & 0.86 & 0.81 & 0.83 & 0.73 \\
\hline First-year ice $<0.7 \mathrm{~m}$ & 0.47 & 0.32 & 0.85 & 0.80 & 0.80 & 0.70 & 0.96 & 0.90 & 0.88 & 0.77 \\
\hline First-year ice $>0.7 \mathrm{~m}$ & 0.54 & 0.33 & 0.93 & 0.87 & 0.88 & 0.77 & 0.96 & 0.90 & 0.88 & 0.77 \\
\hline
\end{tabular}

0.05-0.06. Our measured values fall within the range of all-wave albedos reported by Zhou et al. (2001) for snow-covered sea ice in the Ross Sea in summer (January-February). They reported frequent new snowfall as well as melting snow, but melt ponds were absent. Their average all-wave albedo under cloudy sky increased from 0.75 at $67^{\circ} \mathrm{S}$ to 0.84 at $74^{\circ} \mathrm{S}$. Somewhat lower values were reported by Wendler et al. (2000) in the same region, with a mean albedo for snow-covered first-year ice of 0.74 , but this may have been under clear sky.

To assign the remaining entries in Table 1 for melting snow in December-January-February (DJF), we assume that the change in albedo from SON to DJF is proportional to the SON albedo and to the albedo difference found for thick snow over thick first-year ice. For example, the DJF albedo for thin snow over nilas is estimated as follows:

$$
\alpha_{\mathrm{DJF}}=0.42-(0.81-0.75) \frac{0.42}{0.81}=0.39 .
$$

Our table lacks entries for other summer ice types: slush, melt-ponds, and melting bare ice. These types of surface are much more common in the Arctic than in the Antarctic. Their spectral albedos are given by Grenfell and Perovich (1984) and Perovich et al. (2002), and a table analogous to Table 1 for melting forms of Arctic sea ice has been published by Perovich et al. (1986).

\section{e. Albedos for AVHRR channels and for GCM bands}

The spectral measurements in Figs. 1-3, as well as those in Fig. 11 of ABW, can be integrated over narrow bands to obtain albedos $\left(\alpha_{\mathrm{ch}}\right)$ of sea ice for satellite channels of any bandwidth:

$$
\alpha_{\mathrm{ch}}=\frac{\int \alpha_{\lambda} s_{\lambda} F_{\lambda} d \lambda}{\int s_{\lambda} F_{\lambda} d \lambda},
$$

where $s_{\lambda}$ is the spectral sensitivity function for the channel. Sea ice can be seen from satellites using the solar spectrum only if clouds are absent, so we compute $\alpha_{c h}$ in (3) using the clear-sky spectrum of $F_{\lambda}$.

We have computed $\alpha_{\mathrm{ch}}$ for the Advanced Very High Resolution Radiometer (AVHRR), which has been deployed routinely on National Oceanic and Atmospheric Administration's (NOAA's) polar-orbiting satellites since 1978. The spectral responses of channels 1 and 2 have been maintained nearly unchanged on successive satellites; their bandwidths are approximately 550-700 nm for channel 1 ("visible") and 700-1050 nm for channel 2 ("near infrared"). We used the spectral response functions for the NOAA-11 satellite, launched in 1988. The channel albedos are given in Table 2. The albedo is lower in channel 2 than in channel 1 because the spectral albedo decreases with wavelength as shown in Figs. $1-3$. Table 2 indicates that channel 1 is more sensitive than channel 2 to the thickness of snow-free ice, as can also be seen in Fig. 1.

General circulation models (GCMs) vary in their treatment of solar radiation. Many break the solar spectrum into just two bands, visible $(\lambda<700 \mathrm{~nm})$ and NIR $(\lambda>700 \mathrm{~nm})$. Approximately half the solar energy is in each band. This is also a convenient division for vegetated surfaces, because the albedo of green plants is low in the visible but rises sharply at $\lambda \approx 700 \mathrm{~nm}$ (e.g., Fig. 8.29 of Gates 1980). Albedos for these two bands are given in Table 3. For the NIR albedo, separate values are given for clear and cloudy sky, but for the visible albedo only one value is given. This is because clouds are nonabsorbing at visible wavelengths, so the visible albedo under a cloudy sky is the same as under a clear sky (at an average solar zenith angle of about $60^{\circ}$ ). Most of the time, it is the cloudy-sky albedo that is relevant because the average cloud cover in spring and summer over the Antarctic sea ice zone exceeds 80\% (Warren et al. 1988). 
TABLE 3. Representative albedos of surface types in the East Antarctic sea ice zone in spring and summer, for visible $(\lambda<700 \mathrm{~nm})$ and NIR $(\lambda>700 \mathrm{~nm})$ bands commonly used in GCMs. Values in bold are derived from measurements; all others were interpolated or extrapolated using the method illustrated in Fig. 5.

\begin{tabular}{|c|c|c|c|c|c|c|c|c|c|c|c|c|c|c|c|}
\hline \multirow[b]{3}{*}{ Ice type } & \multicolumn{3}{|c|}{ No snow } & \multicolumn{6}{|c|}{ Thin snow $(<3 \mathrm{~cm})$} & \multicolumn{6}{|c|}{ Thick snow $(>3 \mathrm{~cm})$} \\
\hline & \multirow[b]{2}{*}{ VIS } & \multirow{2}{*}{$\begin{array}{l}\text { NIR } \\
\text { clear }\end{array}$} & \multirow{2}{*}{$\begin{array}{l}\text { NIR } \\
\text { cloud }\end{array}$} & \multicolumn{2}{|c|}{ VIS } & \multicolumn{2}{|c|}{ NIR clear } & \multicolumn{2}{|c|}{ NIR cloud } & \multicolumn{2}{|c|}{ VIS } & \multicolumn{2}{|c|}{ NIR clear } & \multicolumn{2}{|c|}{ NIR cloud } \\
\hline & & & & SON & DJF & SON & DJF & SON & DJF & SON & DJF & SON & DJF & SON & DJF \\
\hline Open wa & 0.07 & 0.06 & 0.06 & - & - & - & - & - & - & - & - & - & - & - & - \\
\hline Grease & 0.11 & 0.06 & 0.07 & - & - & - & - & - & - & - & - & - & - & - & - \\
\hline Nilas & 0.18 & 0.11 & 0.12 & 0.50 & 0.47 & 0.33 & 0.28 & 0.36 & 0.32 & - & - & - & - & - & - \\
\hline Young grey & 0.30 & 0.19 & 0.21 & 0.64 & 0.61 & 0.44 & 0.38 & 0.49 & 0.44 & 0.80 & 0.76 & 0.60 & 0.52 & 0.66 & 0.59 \\
\hline Young grey-white & 0.39 & 0.23 & 0.25 & 0.73 & 0.69 & 0.52 & 0.45 & 0.57 & 0.51 & 0.87 & 0.82 & 0.62 & 0.53 & 0.68 & 0.60 \\
\hline First-year, $<0.7 \mathrm{~m}$ & 0.54 & 0.27 & 0.29 & 0.85 & 0.81 & 0.60 & 0.52 & 0.66 & 0.59 & 0.96 & 0.91 & 0.65 & 0.56 & 0.72 & 0.64 \\
\hline First-year, $>0.7 \mathrm{~m}$ & 0.67 & 0.29 & 0.31 & 0.94 & 0.89 & 0.65 & 0.56 & 0.72 & 0.64 & 0.96 & 0.91 & 0.65 & 0.56 & 0.72 & 0.64 \\
\hline
\end{tabular}

\section{Average surface albedos by region and season}

\section{a. ASPeCt observations}

The ASPeCt dataset includes more than 21000 observations from ships for the years 1980-2000, but approximately $20 \%$ of the reports lack information about snow cover on the ice. Data selected for this study were from the period 1980-2000. We have analyzed the observations that were complete, including snow information; there are 15690 of them. Repeated hourly observations made when a ship was stuck or nearly stationary in thick ice would cause a bias in the averages. We therefore followed the procedure of $\mathrm{ABW}$, removing from the dataset observations made less than 6 nautical miles apart, because the average speed of an unhindered icebreaker is about $6 \mathrm{kt}$. This thinning of the dataset resulted in 10016 observations. The locations of the observations made during the seasons of high sun (spring and summer) are shown in Fig. 6. Each observation includes information on the concentration, thickness, and snow cover properties of the three dominant ice thickness categories present.

Albedos were assigned from Table 1 for each ice type reported in each observation, and an average broadband albedo was then obtained for each observation by weighting for the fractional coverage reported for each surface type (if more than one type was reported). The same was done for the GCM albedos using Table 3. The observations were binned into the five longitudinal sectors indicated in Fig. 6 and into the four meteorological seasons: spring (SON), summer (DJF), autumn [MarchApril-May (MAM)], and winter [June-July-August (JJA)]. These five longitudinal sectors are the same sectors used for the satellite microwave analyses of ice distribution (Gloersen et al. 1992, their Fig. 4.1.3). Within each sector, the observations were binned into $2.5^{\circ}$ latitude zones. A seasonal average albedo for each geographical grid box was then obtained as the average of all observations in the grid box for a particular season. The average albedo was computed both for the total area and for the "ice-only" area (i.e., excluding the open-water fraction).

The distribution of albedos for all observations, irrespective of season and location, is shown in Fig. 7. These are the albedos including the water fraction. The large number of observations in the lowest-albedo bin are mostly regions of open water within the sea ice zone. The large number of high albedos are from snowcovered first-year ice of high concentration. The albedos in the middle range can be obtained for uniform sheets of young ice (nilas, grey ice, and grey-white ice), but most of these intermediate albedos actually come from mixed scenes consisting of snow-covered first-year ice interspersed with leads of open water or new dark ice.

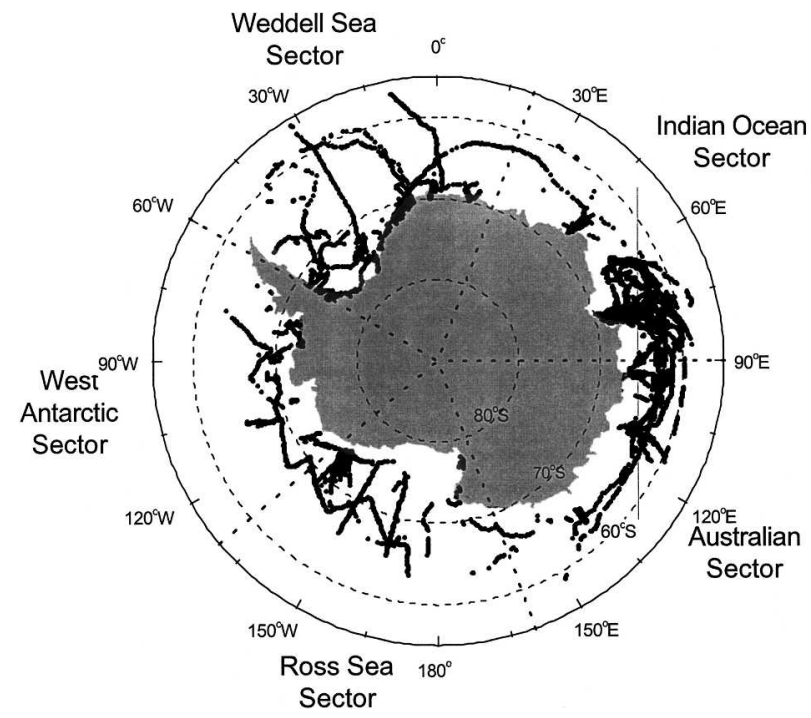

FIG. 6. Locations of visual shipboard ice observations in the ASPeCt database for spring and summer seasons (Sep-Feb), 1980-2000. Five longitudinal sectors are identified for the analysis. 


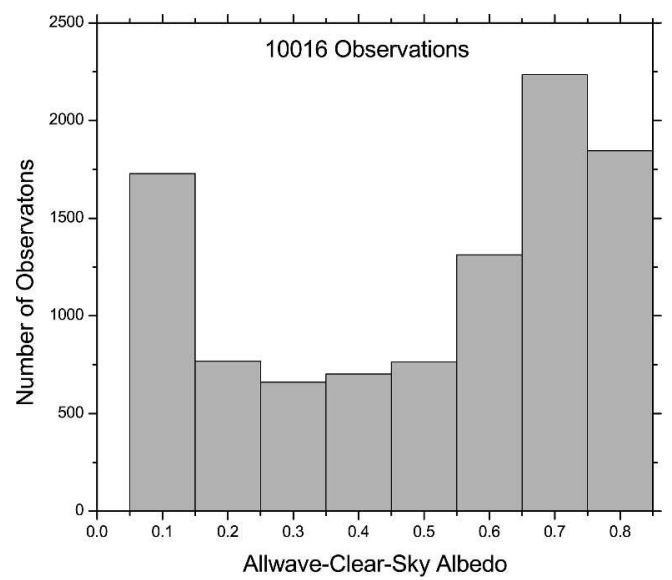

FIG. 7. Frequency distribution of albedo for the ASPeCt observations, representing an area of $1-\mathrm{km}$ radius surrounding the ship.

Figure 8 shows the ice-only albedo as a function of latitude, for each of the five longitudinal sectors. The plot for each sector terminates at the coast of Antarctica; the plots for the different sectors therefore terminate at different latitudes. The number of observations is given for each grid box. These albedos were computed for all seasons, but the figure shows results only for spring and summer, the two seasons with large amounts of incident solar energy. The ice-only albedos are only slightly lower in summer than in spring. This is because decaying first-year ice retains its snow cover and does not develop melt ponds. Summertime ice-only albedos for the Arctic would be lower. [Perovich et al. (2002) reported an average ice-only albedo of 0.4 at the end of July. The unponded ice had an albedo of 0.65 , but ponds covered a large fraction of the ice area.]

In both seasons in most of the sectors, the ice-only albedo is nearly independent of latitude. In the summer, this is because there is usually only one ice type throughout the seasonal sea ice zone, melting first-year ice. In spring, new ice is forming wherever leads open, and this happens everywhere in the sea ice zone.

\section{b. Ice concentrations from SSM/I}

To get area-average ice concentrations, we use satellite observations. Natural microwave emission measured by the Special Sensor Microwave Imager (SSM/I) has been analyzed for sea ice concentration by the "bootstrap" algorithm (Comiso 1986); the ice concentrations on a $25-\mathrm{km}$ grid are available from the National Snow and Ice Data Center at the University of Colorado (Comiso 2002). We used the SSM/I data for the 13 yr 1988-2000 and averaged them for each of the four seasons for each of our grid boxes; the results for the spring and summer seasons are shown in Fig. 9. They show a gradual increase in concentration as one moves in from the ice margin, as expected for grid cells as large
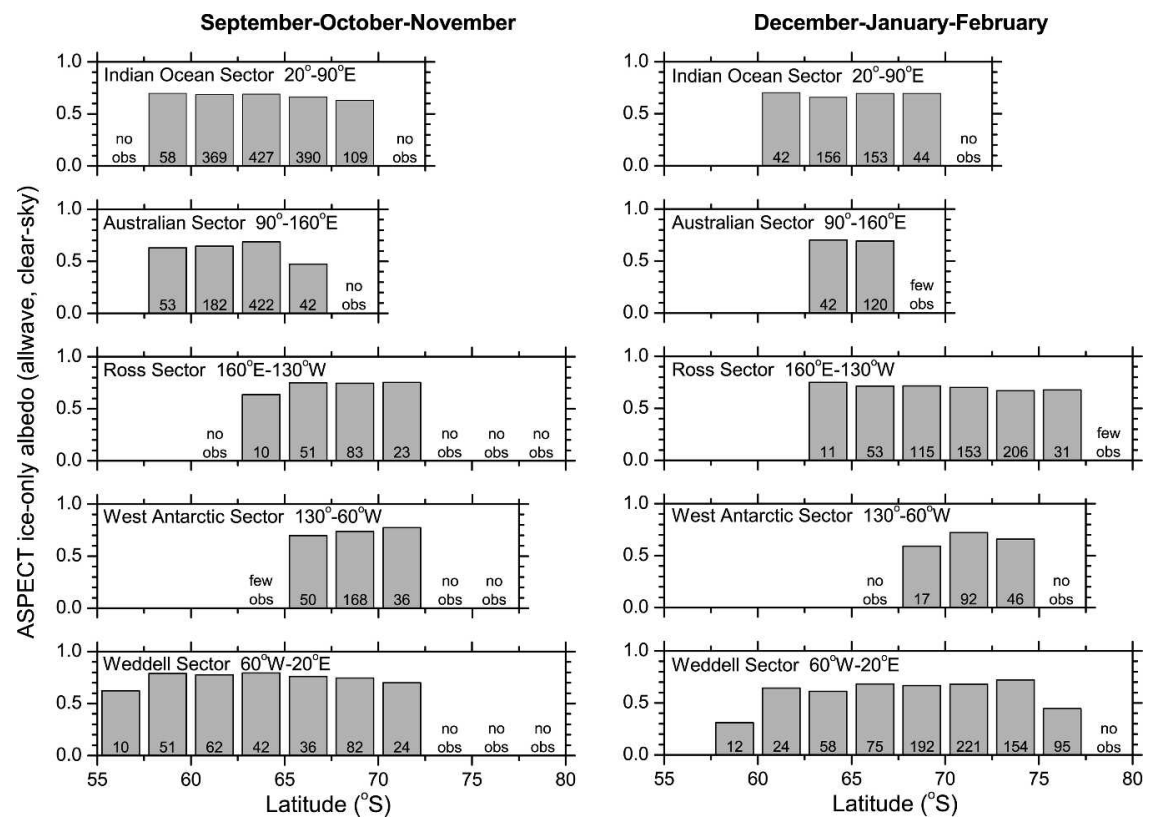

FIG. 8. Average broadband solar albedo for the ice area only, as a function of latitude, from the ASPeCt shipboard observations. Plots are shown for two seasons for each of the five sectors. The number of observations contributing to the average is given at the bottom of each bar. 

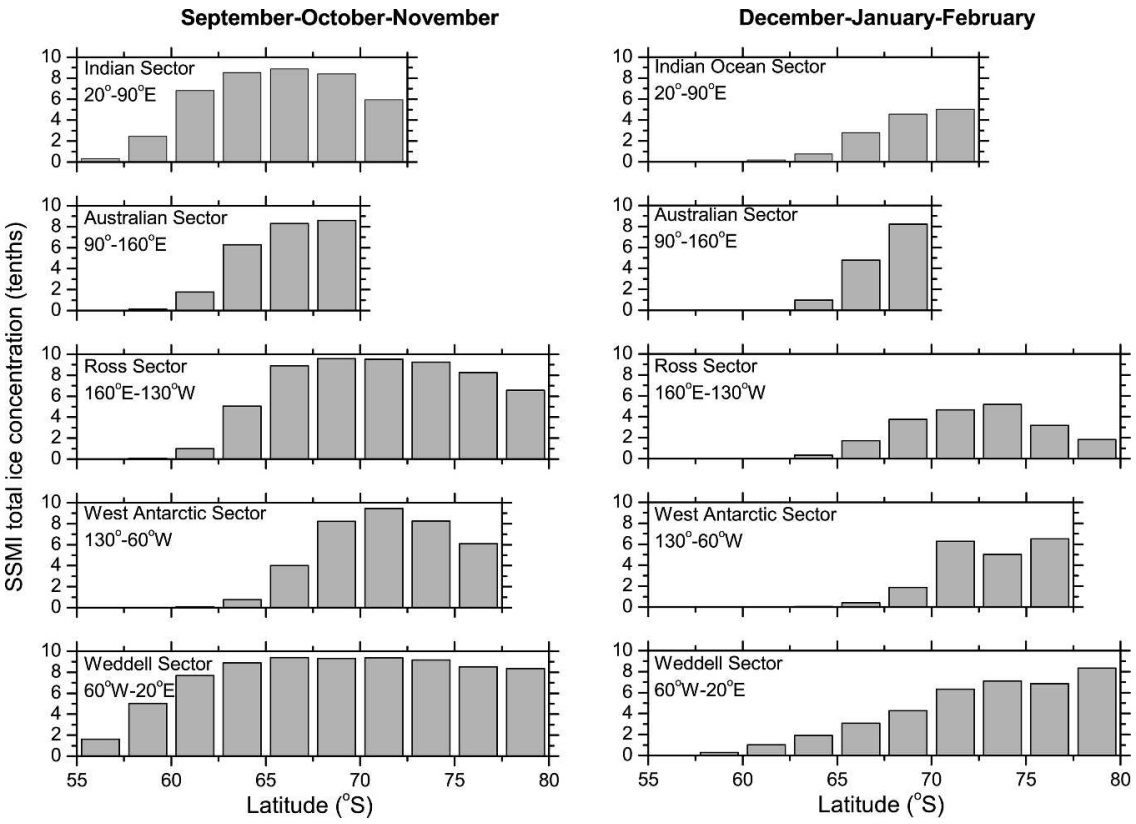

FIG. 9. Average ice concentration as a function of latitude, from satellite passive microwave observations by the SSM/I instrument, using the bootstrap algorithm, for the years 1988-2000. Plots are shown for two seasons for each of the five sectors.

as $25 \mathrm{~km}$. Concentrations are much lower in summer than in spring, except for high-latitude parts of the West Antarctic and Weddell sectors, where multiyear ice is common. (A high concentration is also shown for the Australian sector, $67.5^{\circ}-70^{\circ} \mathrm{S}$ in summer, but this zone is mostly continental, so the value given applies only to the small oceanic region $147^{\circ}-160^{\circ} \mathrm{E}$.)

The ice-only albedos, $\alpha_{i}$, from Fig. 8 , are combined with the ice concentrations, $c_{i}$, from Fig. 9, to obtain area-average albedos $\alpha$ :

$$
\alpha=\alpha_{i} c_{i}+\alpha_{w}\left(1-c_{i}\right)
$$

where $\alpha_{w}$ is the albedo of open water (0.07 for visible, 0.06 for NIR, and 0.07 for broadband solar). These area-average albedos are given in Tables 4 and 5 for all four seasons and for both clear-sky and cloudy-sky incident irradiance. The clear-sky albedos are plotted in Fig. 10 for spring and summer. Comparison of Figs. 8, 9, and 10 shows that most of the regional variation of albedo is due to regional variation in ice concentration, not ice type.

Area-averaged albedos are also computed for the GCM visible and near-infrared bands (Tables 6-8). They may be useful for comparison with predictions of climate models.

\section{Conclusions}

Antarctic sea ice is a mixture of diverse ice types with a variety of albedos ranging from 0.07 to 0.87 . New ice has low albedo, which increases gradually as the ice thickens, but then jumps dramatically when it acquires even just a thin snow cover. In most regions in all seasons, most of the ice is snow covered. However, the ice is pushed northward by the winds and currents, so in most $2.5^{\circ}$ grid boxes there is a substantial fraction of open water. Therefore, the main determinant of areaaveraged albedo is ice concentration. With climatic change, the albedo of the Antarctic Ocean could change for any of several reasons: change in ice margin position, change in ice concentration within the pack, change in the mix of ice types, and change in snow cover, snow depth, or snow wetness.

Acknowledgments. We thank Ian Allison, leader of the Glaciology Section of the Australian Antarctic Division, for sponsoring this project and for his support as voyage leader in 2000 . We thank Martin Betts, the voyage leader in both 1988 and 1996, and the crews of Icebird, Aurora Australis, and Polar Bird, for arranging logistics and assisting our project. SGW, REB, and TCG acknowledge the hospitality of the Cooperative Research Centre for Antarctic and Southern Ocean Studies during preparation for fieldwork at the University of Tasmania. Kelvin Michael, Collin Roesler, and Melanie Fitzpatrick assisted with the fieldwork, and many sea ice observers have contributed to the data contained within the ASPeCt data archive. We benefited from discussions with Collin Roesler and 

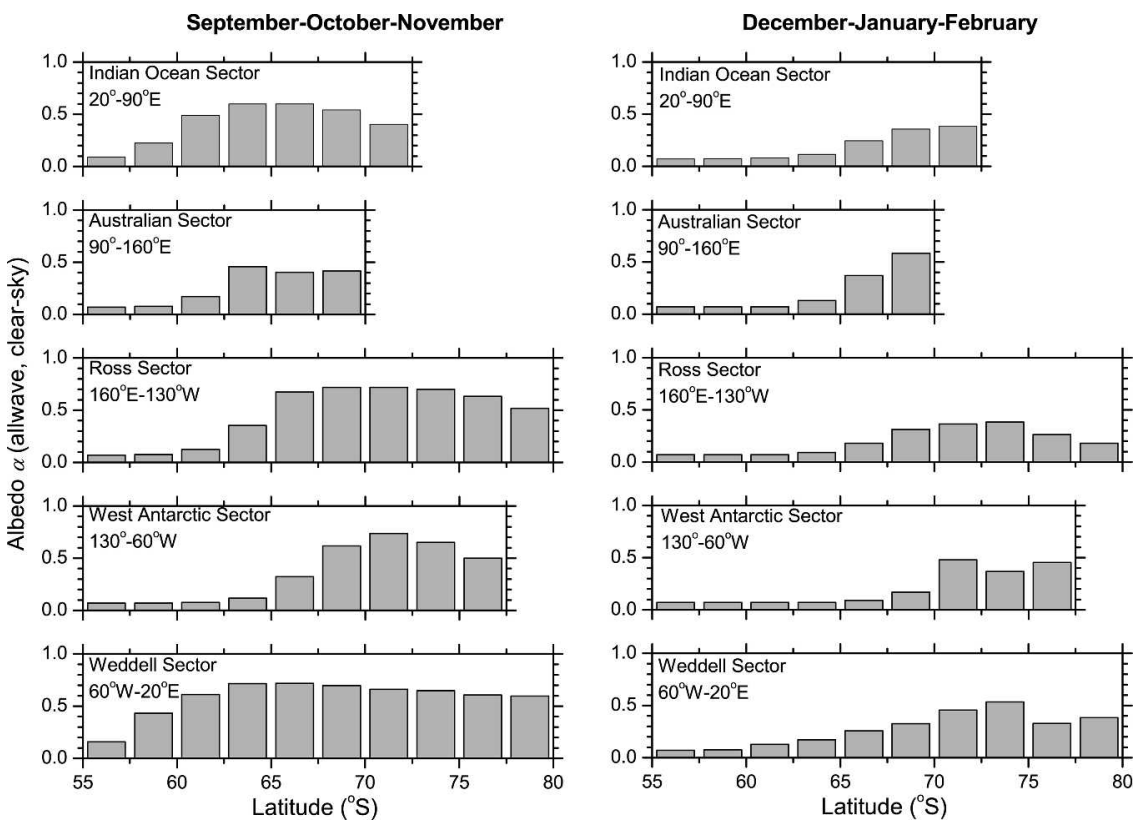

FIG. 10. Average broadband solar albedo as a function of latitude, including both ice and water, combining ASPeCt ice-only albedos from Fig. 7 together with SSM/I ice concentrations from Fig. 9 and using (4).

TABLE 4. Average broadband solar (all-wave) albedo for clear sky with solar zenith angle $60^{\circ}$ in $2.5^{\circ}$ latitude zones, obtained from (4) for four seasons, for the five longitudinal sectors identified in Fig. 6: Indian Ocean, Australian, Ross Sea, West Antarctic, and Weddell Sea sectors (denoted as Ind, Aust, Ross, West, and Wedd, respectively). The values for SON and DJF are plotted in Fig. 10.

\begin{tabular}{|c|c|c|c|c|c|c|c|c|c|c|}
\hline \multicolumn{11}{|c|}{ All-wave clear sky } \\
\hline \multirow{2}{*}{$\begin{array}{c}\text { Latitude } \\
\text { range }\left({ }^{\circ} \mathrm{S}\right)\end{array}$} & \multicolumn{5}{|c|}{ SON } & \multicolumn{5}{|c|}{ DJF } \\
\hline & Ind & Aust & Ross & West & Wedd & Ind & Aust & Ross & West & Wedd \\
\hline $55.0-57.5$ & 0.09 & 0.07 & 0.07 & 0.07 & 0.16 & 0.07 & 0.07 & 0.07 & 0.07 & 0.07 \\
\hline $57.5-60.0$ & 0.22 & 0.08 & 0.07 & 0.07 & 0.43 & 0.07 & 0.07 & 0.07 & 0.07 & 0.08 \\
\hline $60.0-62.5$ & 0.49 & 0.17 & 0.13 & 0.07 & 0.61 & 0.08 & 0.07 & 0.07 & 0.07 & 0.13 \\
\hline $62.5-65.0$ & 0.60 & 0.46 & 0.36 & 0.12 & 0.72 & 0.12 & 0.13 & 0.09 & 0.07 & 0.17 \\
\hline $65.0-67.5$ & 0.60 & 0.40 & 0.67 & 0.32 & 0.72 & 0.24 & 0.37 & 0.18 & 0.09 & 0.26 \\
\hline $67.5-70.0$ & 0.54 & 0.42 & 0.72 & 0.62 & 0.70 & 0.36 & 0.58 & 0.31 & 0.17 & 0.33 \\
\hline $70.0-72.5$ & 0.40 & - & 0.72 & 0.74 & 0.66 & 0.38 & - & 0.36 & 0.48 & 0.46 \\
\hline $72.5-75.0$ & - & - & 0.70 & 0.65 & 0.65 & - & - & 0.38 & 0.37 & 0.53 \\
\hline $75.0-77.5$ & - & - & 0.63 & 0.50 & 0.61 & - & - & 0.26 & 0.45 & 0.33 \\
\hline $77.5-80.0$ & - & - & 0.52 & - & 0.60 & - & - & 0.18 & - & 0.38 \\
\hline \multirow{2}{*}{$\begin{array}{c}\text { Latitude } \\
\text { range }\left({ }^{\circ} \mathrm{S}\right)\end{array}$} & \multicolumn{5}{|c|}{ MAM } & \multicolumn{5}{|c|}{ JJA } \\
\hline & Ind & Aust & Ross & West & Wedd & Ind & Aust & Ross & West & Wedd \\
\hline $55.0-57.5$ & 0.07 & 0.07 & 0.07 & 0.07 & 0.07 & 0.07 & 0.07 & 0.07 & 0.07 & 0.13 \\
\hline $57.5-60.0$ & 0.07 & 0.07 & 0.07 & 0.07 & 0.07 & 0.11 & 0.07 & 0.07 & 0.07 & 0.32 \\
\hline $60.0-62.5$ & 0.07 & 0.07 & 0.07 & 0.07 & 0.11 & 0.33 & 0.17 & 0.10 & 0.08 & 0.52 \\
\hline $62.5-65.0$ & 0.13 & 0.18 & 0.08 & 0.07 & 0.20 & 0.58 & 0.50 & 0.37 & 0.11 & 0.65 \\
\hline $65.0-67.5$ & 0.28 & 0.41 & 0.16 & 0.08 & 0.28 & 0.66 & 0.49 & 0.64 & 0.24 & 0.69 \\
\hline $67.5-70.0$ & 0.34 & 0.49 & 0.39 & 0.18 & 0.36 & 0.51 & 0.49 & 0.75 & 0.56 & 0.64 \\
\hline $70.0-72.5$ & 0.31 & - & 0.45 & 0.51 & 0.44 & 0.38 & - & 0.74 & 0.70 & 0.73 \\
\hline $72.5-75.0$ & - & - & 0.55 & 0.57 & 0.47 & - & - & 0.72 & 0.64 & 0.71 \\
\hline $75.0-77.5$ & - & - & 0.51 & 0.54 & 0.47 & - & - & 0.71 & 0.49 & 0.66 \\
\hline $77.5-80.0$ & - & - & 0.32 & - & 0.48 & - & - & 0.61 & - & 0.66 \\
\hline
\end{tabular}


TABLE 5. Average broadband solar (all-wave) albedo for cloudy sky in $2.5^{\circ}$ latitude zones, obtained from (4), for four seasons, for the five longitudinal sectors identified in Fig. 6.

\begin{tabular}{|c|c|c|c|c|c|c|c|c|c|c|}
\hline \multicolumn{11}{|c|}{ All-wave cloudy sky } \\
\hline \multirow{2}{*}{$\begin{array}{l}\text { Latitude } \\
\text { range }\left({ }^{\circ} \mathrm{S}\right)\end{array}$} & \multicolumn{5}{|c|}{ SON } & \multicolumn{5}{|c|}{ DJF } \\
\hline & Ind & Aust & Ross & West & Wedd & Ind & Aust & Ross & West & Wedd \\
\hline $55.0-57.5$ & 0.09 & 0.07 & 0.07 & 0.07 & 0.17 & 0.07 & 0.07 & 0.07 & 0.07 & 0.07 \\
\hline $57.5-60.0$ & 0.24 & 0.08 & 0.08 & 0.07 & 0.46 & 0.07 & 0.07 & 0.07 & 0.07 & 0.08 \\
\hline $60.0-62.5$ & 0.53 & 0.18 & 0.13 & 0.08 & 0.65 & 0.08 & 0.07 & 0.07 & 0.07 & 0.13 \\
\hline $62.5-65.0$ & 0.64 & 0.49 & 0.38 & 0.12 & 0.77 & 0.12 & 0.14 & 0.09 & 0.07 & 0.18 \\
\hline $65.0-67.5$ & 0.64 & 0.44 & 0.72 & 0.34 & 0.77 & 0.26 & 0.40 & 0.19 & 0.09 & 0.28 \\
\hline $67.5-70.0$ & 0.58 & 0.45 & 0.77 & 0.66 & 0.75 & 0.39 & 0.64 & 0.34 & 0.18 & 0.35 \\
\hline $70.0-72.5$ & 0.43 & - & 0.77 & 0.79 & 0.71 & 0.42 & - & 0.39 & 0.52 & 0.50 \\
\hline $72.5-75.0$ & - & - & 0.75 & 0.70 & 0.70 & - & - & 0.41 & 0.40 & 0.59 \\
\hline $75.0-77.5$ & - & - & 0.68 & 0.53 & 0.65 & - & - & 0.28 & 0.50 & 0.35 \\
\hline $77.5-80.0$ & - & - & 0.56 & - & 0.64 & - & - & 0.19 & - & 0.42 \\
\hline \multirow{2}{*}{$\begin{array}{l}\text { Latitude } \\
\text { range }\left({ }^{\circ} \mathrm{S}\right)\end{array}$} & \multicolumn{5}{|c|}{ MAM } & \multicolumn{5}{|c|}{ JJA } \\
\hline & Ind & Aust & Ross & West & Wedd & Ind & Aust & Ross & West & Wedd \\
\hline $55.0-57.5$ & 0.07 & 0.07 & 0.07 & 0.07 & 0.07 & 0.07 & 0.07 & 0.07 & 0.07 & 0.13 \\
\hline $57.5-60.0$ & 0.07 & 0.07 & 0.07 & 0.07 & 0.07 & 0.11 & 0.07 & 0.07 & 0.07 & 0.34 \\
\hline $60.0-62.5$ & 0.07 & 0.07 & 0.07 & 0.07 & 0.11 & 0.35 & 0.17 & 0.10 & 0.08 & 0.56 \\
\hline $62.5-65.0$ & 0.14 & 0.19 & 0.08 & 0.07 & 0.21 & 0.62 & 0.54 & 0.39 & 0.11 & 0.69 \\
\hline $65.0-67.5$ & 0.30 & 0.44 & 0.17 & 0.08 & 0.30 & 0.71 & 0.53 & 0.68 & 0.25 & 0.74 \\
\hline $67.5-70.0$ & 0.37 & 0.52 & 0.41 & 0.20 & 0.38 & 0.55 & 0.53 & 0.80 & 0.60 & 0.69 \\
\hline $70.0-72.5$ & 0.33 & - & 0.48 & 0.55 & 0.48 & 0.41 & - & 0.80 & 0.75 & 0.78 \\
\hline $72.5-75.0$ & - & - & 0.59 & 0.61 & 0.51 & - & - & 0.77 & 0.69 & 0.76 \\
\hline $75.0-77.5$ & - & - & 0.54 & 0.58 & 0.50 & - & - & 0.76 & 0.52 & 0.71 \\
\hline $77.5-80.0$ & - & - & 0.34 & - & 0.52 & - & - & 0.65 & - & 0.70 \\
\hline
\end{tabular}

TABLE 6. Average albedo for the visible band $(\lambda<700 \mathrm{~nm})$ in $2.5^{\circ}$ latitude zones, obtained from (4), for four seasons, for the five longitudinal sectors identified in Fig. 6. Table 3 was used for the albedos of each ice type. (In this spectral band, the albedo is nearly the same whether the sky is clear or cloudy.)

\begin{tabular}{|c|c|c|c|c|c|c|c|c|c|c|}
\hline \multicolumn{11}{|c|}{ GCM visible band $(\lambda<700 \mathrm{~nm})$ clear sky and cloudy sky } \\
\hline \multirow{2}{*}{$\begin{array}{l}\text { Latitude } \\
\text { range }\left({ }^{\circ} \mathrm{S}\right)\end{array}$} & \multicolumn{5}{|c|}{ SON } & \multicolumn{5}{|c|}{ DJF } \\
\hline & Ind & Aust & Ross & West & Wedd & Ind & Aust & Ross & West & Wedd \\
\hline $55.0-57.5$ & 0.10 & 0.07 & 0.07 & 0.07 & 0.18 & 0.07 & 0.07 & 0.07 & 0.07 & 0.07 \\
\hline $57.5-60.0$ & 0.25 & 0.08 & 0.08 & 0.07 & 0.51 & 0.07 & 0.07 & 0.07 & 0.07 & 0.08 \\
\hline $60.0-62.5$ & 0.58 & 0.19 & 0.14 & 0.08 & 0.72 & 0.08 & 0.07 & 0.07 & 0.07 & 0.14 \\
\hline $62.5-65.0$ & 0.71 & 0.54 & 0.43 & 0.13 & 0.84 & 0.13 & 0.15 & 0.10 & 0.07 & 0.20 \\
\hline $65.0-67.5$ & 0.71 & 0.48 & 0.80 & 0.37 & 0.85 & 0.29 & 0.45 & 0.21 & 0.10 & 0.30 \\
\hline $67.5-70.0$ & 0.64 & 0.50 & 0.85 & 0.73 & 0.82 & 0.43 & 0.71 & 0.37 & 0.19 & 0.39 \\
\hline $70.0-72.5$ & 0.47 & - & 0.85 & 0.87 & 0.78 & 0.46 & - & 0.43 & 0.58 & 0.55 \\
\hline $72.5-75.0$ & - & - & 0.83 & 0.77 & 0.77 & - & - & 0.46 & 0.44 & 0.64 \\
\hline $75.0-77.5$ & - & - & 0.75 & 0.58 & 0.72 & - & - & 0.31 & 0.54 & 0.39 \\
\hline $77.5-80.0$ & - & - & 0.61 & - & 0.71 & - & - & 0.21 & - & 0.46 \\
\hline \multirow{2}{*}{$\begin{array}{c}\text { Latitude } \\
\text { range }\left({ }^{\circ} \mathrm{S}\right)\end{array}$} & \multicolumn{5}{|c|}{ MAM } & \multicolumn{5}{|c|}{ JJA } \\
\hline & Ind & Aust & Ross & West & Wedd & Ind & Aust & Ross & West & Wedd \\
\hline $55.0-57.5$ & 0.07 & 0.07 & 0.07 & 0.07 & 0.07 & 0.07 & 0.07 & 0.07 & 0.07 & 0.14 \\
\hline $57.5-60.0$ & 0.07 & 0.07 & 0.07 & 0.07 & 0.07 & 0.12 & 0.07 & 0.07 & 0.07 & 0.37 \\
\hline $60.0-62.5$ & 0.07 & 0.07 & 0.07 & 0.07 & 0.12 & 0.38 & 0.19 & 0.10 & 0.08 & 0.61 \\
\hline $62.5-65.0$ & 0.15 & 0.20 & 0.08 & 0.07 & 0.23 & 0.67 & 0.59 & 0.42 & 0.11 & 0.76 \\
\hline $65.0-67.5$ & 0.32 & 0.48 & 0.18 & 0.09 & 0.32 & 0.77 & 0.58 & 0.74 & 0.27 & 0.81 \\
\hline $67.5-70.0$ & 0.40 & 0.57 & 0.45 & 0.22 & 0.41 & 0.60 & 0.58 & 0.88 & 0.66 & 0.76 \\
\hline $70.0-72.5$ & 0.36 & - & 0.53 & 0.60 & 0.52 & 0.44 & - & 0.88 & 0.83 & 0.86 \\
\hline $72.5-75.0$ & - & - & 0.65 & 0.68 & 0.55 & - & - & 0.85 & 0.76 & 0.84 \\
\hline $75.0-77.5$ & - & - & 0.59 & 0.64 & 0.55 & - & - & 0.83 & 0.57 & 0.78 \\
\hline $77.5-80.0$ & - & - & 0.37 & - & 0.56 & - & - & 0.71 & - & 0.77 \\
\hline
\end{tabular}


TABLE 7. Average albedo for the near-IR band $(\lambda>700 \mathrm{~nm})$ under clear sky in $2.5^{\circ}$ latitude zones, obtained from (4), for four seasons, for the five longitudinal sectors identified in Fig. 6. Table 3 was used for the albedos of each ice type.

\begin{tabular}{|c|c|c|c|c|c|c|c|c|c|c|}
\hline \multicolumn{11}{|c|}{ GCM NIR band $(\lambda>700 \mathrm{~nm})$ clear sky } \\
\hline \multirow{2}{*}{$\begin{array}{c}\text { Latitude } \\
\text { range }\left({ }^{\circ} \mathrm{S}\right)\end{array}$} & \multicolumn{5}{|c|}{ SON } & \multicolumn{5}{|c|}{ DJF } \\
\hline & Ind & Aust & Ross & West & Wedd & Ind & Aust & Ross & West & Wedd \\
\hline $55.0-57.5$ & 0.08 & 0.06 & 0.06 & 0.06 & 0.13 & 0.06 & 0.06 & 0.06 & 0.06 & 0.06 \\
\hline $57.5-60.0$ & 0.18 & 0.07 & 0.06 & 0.06 & 0.35 & 0.06 & 0.06 & 0.06 & 0.06 & 0.07 \\
\hline $60.0-62.5$ & 0.39 & 0.14 & 0.10 & 0.06 & 0.49 & 0.07 & 0.06 & 0.06 & 0.06 & 0.10 \\
\hline $62.5-65.0$ & 0.48 & 0.37 & 0.27 & 0.10 & 0.58 & 0.09 & 0.10 & 0.08 & 0.06 & 0.13 \\
\hline $65.0-67.5$ & 0.48 & 0.32 & 0.54 & 0.26 & 0.58 & 0.19 & 0.28 & 0.14 & 0.08 & 0.20 \\
\hline $67.5-70.0$ & 0.43 & 0.33 & 0.58 & 0.50 & 0.56 & 0.27 & 0.43 & 0.24 & 0.13 & 0.25 \\
\hline $70.0-72.5$ & 0.32 & - & 0.58 & 0.59 & 0.52 & 0.29 & - & 0.28 & 0.36 & 0.34 \\
\hline $72.5-75.0$ & - & - & 0.56 & 0.52 & 0.51 & - & - & 0.29 & 0.28 & 0.40 \\
\hline $75.0-77.5$ & - & - & 0.51 & 0.40 & 0.48 & - & - & 0.20 & 0.34 & 0.25 \\
\hline $77.5-80.0$ & - & - & 0.42 & - & 0.47 & - & - & 0.14 & - & 0.29 \\
\hline \multirow{2}{*}{$\begin{array}{c}\text { Latitude } \\
\text { range }\left({ }^{\circ} S\right)\end{array}$} & \multicolumn{5}{|c|}{ MAM } & \multicolumn{5}{|c|}{ JJA } \\
\hline & Ind & Aust & Ross & West & $\overline{\text { Wedd }}$ & Ind & Aust & Ross & West & Wedd \\
\hline $55.0-57.5$ & 0.06 & 0.06 & 0.06 & 0.06 & 0.06 & 0.06 & 0.06 & 0.06 & 0.06 & 0.11 \\
\hline $57.5-60.0$ & 0.06 & 0.06 & 0.06 & 0.06 & 0.06 & 0.09 & 0.06 & 0.06 & 0.06 & 0.26 \\
\hline $60.0-62.5$ & 0.06 & 0.06 & 0.06 & 0.06 & 0.09 & 0.27 & 0.14 & 0.08 & 0.07 & 0.42 \\
\hline $62.5-65.0$ & 0.11 & 0.15 & 0.07 & 0.06 & 0.17 & 0.47 & 0.40 & 0.30 & 0.09 & 0.52 \\
\hline $65.0-67.5$ & 0.23 & 0.33 & 0.13 & 0.07 & 0.23 & 0.54 & 0.39 & 0.51 & 0.19 & 0.56 \\
\hline $67.5-70.0$ & 0.28 & 0.39 & 0.31 & 0.15 & 0.29 & 0.42 & 0.39 & 0.60 & 0.45 & 0.52 \\
\hline $70.0-72.5$ & 0.25 & - & 0.36 & 0.41 & 0.36 & 0.31 & - & 0.60 & 0.56 & 0.59 \\
\hline $72.5-75.0$ & - & - & 0.44 & 0.46 & 0.38 & - & - & 0.58 & 0.52 & 0.57 \\
\hline $75.0-77.5$ & - & - & 0.41 & 0.43 & 0.38 & - & - & 0.57 & 0.39 & 0.53 \\
\hline $77.5-80.0$ & - & - & 0.25 & - & 0.39 & - & - & 0.49 & - & 0.53 \\
\hline
\end{tabular}

TABLE 8. Average albedo for the near-IR band $(\lambda>700 \mathrm{~nm})$ under cloudy sky in $2.5^{\circ}$ latitude zones, obtained from (4), for four seasons, for the five longitudinal sectors identified in Fig. 6. Cloudy-sky values from Table 3 were used for the albedos of each ice type.

\begin{tabular}{|c|c|c|c|c|c|c|c|c|c|c|}
\hline \multicolumn{11}{|c|}{ GCM NIR band $(\lambda>700 \mathrm{~nm})$ cloudy sky } \\
\hline \multirow{2}{*}{$\begin{array}{l}\text { Latitude } \\
\text { range }\left({ }^{\circ} \mathrm{S}\right)\end{array}$} & \multicolumn{5}{|c|}{ SON } & \multicolumn{5}{|c|}{ DJF } \\
\hline & Ind & Aust & Ross & West & Wedd & Ind & Aust & Ross & West & Wedd \\
\hline $55.0-57.5$ & 0.08 & 0.06 & 0.06 & 0.06 & 0.14 & 0.06 & 0.06 & 0.06 & 0.06 & 0.06 \\
\hline $57.5-60.0$ & 0.20 & 0.07 & 0.06 & 0.06 & 0.38 & 0.06 & 0.06 & 0.06 & 0.06 & 0.07 \\
\hline $60.0-62.5$ & 0.43 & 0.15 & 0.11 & 0.06 & 0.54 & 0.07 & 0.06 & 0.06 & 0.06 & 0.11 \\
\hline $62.5-65.0$ & 0.53 & 0.40 & 0.30 & 0.10 & 0.64 & 0.10 & 0.11 & 0.08 & 0.06 & 0.14 \\
\hline $65.0-67.5$ & 0.53 & 0.35 & 0.60 & 0.28 & 0.64 & 0.21 & 0.31 & 0.15 & 0.08 & 0.22 \\
\hline $67.5-70.0$ & 0.48 & 0.36 & 0.64 & 0.55 & 0.61 & 0.30 & 0.49 & 0.27 & 0.14 & 0.28 \\
\hline $70.0-72.5$ & 0.35 & - & 0.64 & 0.65 & 0.58 & 0.32 & - & 0.31 & 0.41 & 0.39 \\
\hline $72.5-75.0$ & - & - & 0.62 & 0.58 & 0.57 & - & - & 0.32 & 0.31 & 0.45 \\
\hline $75.0-77.5$ & - & - & 0.56 & 0.44 & 0.53 & - & - & 0.22 & 0.39 & 0.28 \\
\hline $77.5-80.0$ & - & - & 0.46 & - & 0.52 & - & - & 0.15 & - & 0.33 \\
\hline \multirow{2}{*}{$\begin{array}{c}\text { Latitude } \\
\text { range }\left({ }^{\circ} S\right)\end{array}$} & \multicolumn{5}{|c|}{ MAM } & \multicolumn{5}{|c|}{ JJA } \\
\hline & Ind & Aust & Ross & West & Wedd & Ind & Aust & Ross & West & Wedd \\
\hline $55.0-57.5$ & 0.06 & 0.06 & 0.06 & 0.06 & 0.06 & 0.06 & 0.06 & 0.06 & 0.06 & 0.11 \\
\hline $57.5-60.0$ & 0.06 & 0.06 & 0.06 & 0.06 & 0.06 & 0.10 & 0.06 & 0.06 & 0.06 & 0.28 \\
\hline $60.0-62.5$ & 0.06 & 0.06 & 0.06 & 0.06 & 0.09 & 0.29 & 0.15 & 0.09 & 0.07 & 0.46 \\
\hline $62.5-65.0$ & 0.12 & 0.16 & 0.07 & 0.06 & 0.18 & 0.51 & 0.44 & 0.33 & 0.09 & 0.58 \\
\hline $65.0-67.5$ & 0.25 & 0.36 & 0.14 & 0.07 & 0.25 & 0.59 & 0.43 & 0.57 & 0.21 & 0.61 \\
\hline $67.5-70.0$ & 0.30 & 0.43 & 0.34 & 0.16 & 0.31 & 0.46 & 0.43 & 0.66 & 0.50 & 0.57 \\
\hline $70.0-72.5$ & 0.27 & - & 0.40 & 0.45 & 0.39 & 0.34 & - & 0.66 & 0.62 & 0.65 \\
\hline $72.5-75.0$ & - & - & 0.49 & 0.51 & 0.42 & - & - & 0.64 & 0.57 & 0.63 \\
\hline $75.0-77.5$ & - & - & 0.45 & 0.48 & 0.41 & - & - & 0.63 & 0.43 & 0.59 \\
\hline $77.5-80.0$ & - & - & 0.27 & - & 0.43 & - & - & 0.54 & - & 0.58 \\
\hline
\end{tabular}


Thorsten Markus. The research was supported by the Australian Antarctic Division and by Grants OPP-9527245 and OPP-98-15156 from the U.S. National Science Foundation.

\section{REFERENCES}

Allison, I., 1989: The East Antarctic sea ice zone: Ice characteristics and drift. GeoJournal, 18, 103-115.

_ - R. E. Brandt, and S. G. Warren, 1993: East Antarctic sea ice: Albedo, thickness distribution and snow cover. J. Geophys. Res., 98, 12 417-12 429.

Andreas, E. L, and S. F. Ackley, 1982: On the differences in ablation seasons of Arctic and Antarctic sea ice. J. Atmos. Sci., 39, 440-447.

Armstrong, T., B. Roberts, and C. Swithinbank, 1973: Illustrated Glossary of Snow and Ice. Scott Polar Research Institute, 60 pp.

Brandt, R. E., and S. G. Warren, 1993: Solar heating rates and temperature profiles in Antarctic snow and ice. J. Glaciol., 39, 99-110.

— C. S. Roesler, and S. G. Warren, 1999: Spectral albedo, absorptance, and transmittance of Antarctic sea ice. Preprints, Fifth Conf. on Polar Meteorology and Oceanography, Dallas, TX, Amer. Meteor. Soc., 456-459.

Briegleb, B., and V. Ramanathan, 1982: Spectral and diurnal variations in clear sky planetary albedo. J. Appl. Meteor., 21, $1160-1171$.

Comiso, J. C., 1986: Characteristics of Arctic winter sea ice from satellite multispectral microwave observations. J. Geophys. Res., 91, 975-994.

—_ cited 2002: Bootstrap sea ice concentrations for NIMBUS-7 SMMR and DMSP SSM/I. National Snow and Ice Data Center, Boulder, CO. [Available online at http://nsidc.org/data/ nsidc-0079.html.]

Fitzpatrick, M. F., R. E. Brandt, and S. G. Warren, 2004: Transmission of solar radiation by clouds over snow and ice surfaces: A parameterization in terms of optical depth, solar zenith angle, and surface albedo. J. Climate, 17, 266-275.

Gates, D. M., 1980: Biophysical Ecology. Springer-Verlag, 611 pp.

Gloersen, P., W. J. Campbell, D. J. Cavalieri, J. C. Comiso, C. L. Parkinson, and H. J. Zwally, 1992: Arctic and Antarctic Sea Ice, 1978-1987: Satellite passive-microwave observations and analysis. NASA SP-511, National Aeronautics and Space Administration, Washington, DC, $290 \mathrm{pp}$.

Grenfell, T. C., 1983: A theoretical model of the optical properties of sea ice in the visible and near infrared. J. Geophys. Res., 88, 9723-9735.

__ 1986: Surface based passive microwave observations of sea ice in the Bering and Greenland Seas. IEEE Trans. Geosci. Remote Sens., GE-24, 378-382.

— , and D. K. Perovich, 1981: Radiation absorption coefficients of polycrystalline ice from 400-1400 nm. J. Geophys. Res., 86, 7447-7450.

— irradiance in the southern Beaufort Sea. J. Geophys. Res., 89, 3573-3580.

—,- , and J. A. Ogren, 1981: Spectral albedos of an alpine snowpack. Cold Reg. Sci. Technol., 4, 121-127.

— J. C. Comiso, M. A. Lange, H. Eicken, and M. R. Wensnahan, 1994a: Passive microwave observations of the Weddell
Sea during austral winter and early spring. J. Geophys. Res., 99, 9995-10 010.

- S. G. Warren, and P. C. Mullen, 1994b: Reflection of solar radiation by the Antarctic snow surface at ultraviolet, visible, and near-infrared wavelengths. J. Geophys. Res., 99, 18669 18684 .

_ , and Coauthors, 1998: Evolution of electromagnetic signatures of sea ice from initial formation to the establishment of thick first-year ice. IEEE Trans. Geosci. Remote Sens., 36, 1642-1654.

Holland, M. M., and C. M. Bitz, 2003: Polar amplification of climate change in coupled models. Climate Dyn., 21, 221-232.

$\longrightarrow, \ldots$, and A. J. Weaver, 2001: The influence of sea ice physics on simulations of climate change. J. Geophys. Res., 106, $19639-19655$.

Katsaros, K. B., L. A. McMurdie, R. J. Lind, and J. E. DeVault, 1985: Albedo of a water surface, spectral variation, effects of atmospheric transmittance, sun angle, and wind speed. $J$. Geophys. Res., 90, 7313-7321.

Kondratyev, K., 1969: Radiation in the Atmosphere. Academic Press, 912 pp.

Maksym, T., and M. O. Jeffries, 1996: Bulk salinity characteristics of first-year sea ice in the Pacific sector of the Southern Ocean. Antarct. J. U.S., 31, 99-101.

Massom, R. A., and Coauthors, 2001: Snow on Antarctic sea ice. Rev. Geophys., 39, 413-445.

Meehl, G. A., and W. M. Washington, 1990: $\mathrm{CO}_{2}$ climate sensitivity and snow-sea-ice albedo parameterization in an atmospheric GCM coupled to a mixed-layer ocean model. Climate Change, 16, 283-306.

Payne, R. E., 1972: Albedo of the sea surface. J. Atmos. Sci., 29, 959-970.

Pegau, W. S., and C. A. Paulson, 2001: The albedo of Arctic leads in summer. Ann. Glaciol., 33, 221-224.

Perovich, D. K., 1990: The evolution of sea ice optical properties during fall freeze-up. Proc. SPIE, 1302, 520-531.

— properties of young sea ice. J. Glaciol., 96, 331-345.

_ , and J. W. Govoni, 1991: Absorption coefficients of ice from 250 to $400 \mathrm{~nm}$. Geophys. Res. Lett., 18, 1233-1235.

_ and J. A. Richter-Menge, 1994: Surface characteristics of lead ice. J. Geophys. Res., 99, 16 341-16350.

_ , G. A. Maykut, and T. C. Grenfell, 1986: Optical properties of ice and snow in the polar oceans, 1. Observations. Proc. SPIE, 637, 232-241.

_ T. C. Grenfell, B. Light, and P. V. Hobbs, 2002: Seasonal evolution of the albedo of multiyear Arctic sea ice. J. Geophys. Res., 107, 8044, doi:10.1029/2000JC000438.

Rind, D., R. Healy, C. Parkinson, and D. Martinson, 1995: The role of sea ice in $2 \times \mathrm{CO}_{2}$ climate model sensitivity. Part I: The total influence of sea ice thickness and extent. J. Climate, 8, 449-463.

,,--- , and -1997 : The role of sea ice in $2 \times \mathrm{CO}_{2}$ climate model sensitivity. Part II: Hemispheric dependencies. Geophys. Res. Lett., 24, 1491-1494.

Steffen, K., 1986: Atlas of the Sea Ice Types, Deformation Processes and Openings in the Ice. Zürcher Geographisches Schriften, Geographisches Institut, Eidgenössische Technische Hochschule Zürich, Rep. 20, Zürich, Switzerland, 55 pp.

Warren, S. G., 1982: Optical properties of snow. Rev. Geophys. Space Phys., 20, 67-89.

, C. J. Hahn, J. London, R. M. Chervin, and R. L. Jenne, 
1988: Global distribution of total cloud cover and cloud type amounts over the ocean. NCAR Tech. Note NCAR/TN317+STR, 41 pp. + 170 maps.

— C. S. Roesler, and R. E. Brandt, 1997: Solar radiation processes in the East Antarctic sea ice zone. Antarct. J. U.S., 32, 185-187.

— , R. E. Brandt, T. C. Grenfell, and C. P. McKay, 2002: Snowball Earth: Ice thickness on the tropical ocean. J. Geophys. Res., 107, 3167, doi:10.1029/2001JC001123.

Weller, G. E., 1968: The heat budget and heat transfer processes in Antarctic plateau ice and sea ice. ANARE Publication 102, Australian Antarctic Division, Melbourne, Australia, 155 pp. , 1972: Radiation flux investigation. AIDJEX Bull., 14, 28-30.

Wendler, G., B. Moore, D. Dissing, and J. Kelley, 2000: On the radiation characteristics of Antarctic sea ice. Atmos.-Ocean, 38, 349-366.

Wiscombe, W. J., and S. G. Warren, 1980: A model for the spectral albedo of snow. I: Pure snow. J. Atmos. Sci., 37, 27122733.

, R. M. Welch, and W. D. Hall, 1984: The effects of very large drops on cloud absorption. Part I: Parcel models. J. Atmos. Sci., 41, 1336-1355.
Worby, A. P., 1999: Observing Antarctic sea ice: A practical guide for conducting sea ice observations from vessels operating in the Antarctic pack ice. Australian Antarctic Division, Hobart, Australia, CD-ROM.

_ , and I. Allison, 1999: A technique for making ship-based observations of Antarctic sea ice thickness and characteristics. Part I: Observational technique and results. Antarctic Cooperative Research Centre Research Rep. 14, University of Tasmania, Hobart, Australia, 63 pp.

—_, and V. Dirita, 1999: A technique for making ship-based observations of Antarctic sea ice thickness and characteristics. Part II: User operating manual. Antarctic Cooperative Research Centre Research Rep. 14, University of Tasmania, Hobart, Australia, 63 pp.

World Meteorological Organization, 1970: WMO Sea-Ice Nomenclature, Terminology, Codes, and Illustrated Glossary. WMO/ OMM/BMO 259, Tech. Publication 147. World Meteorological Organization, 147 pp.

Zhou, X., S. Li, and K. Morris, 2001: Measurement of all-wave and spectral albedos of snow-covered summer sea ice in the Ross Sea, Antarctica. Ann. Glaciol., 33, 267-274. 